\title{
Integration of Demand Side and Supply Side Energy Management Resources for Optimal Scheduling of Demand Response Loads - South Africa in Focus
}

\author{
Monyei, C. G. ${ }^{1,2,3}$ and Adewumi, A. O. ${ }^{1,2}$ \\ ${ }^{1}$ Applied Artificial Intelligence Research Unit, School of Mathematics, Statistics and \\ Computer Science, University of KwaZulu-Natal, Westville Campus, Private Bag X54001, \\ Durban 4000, South Africa \\ ${ }^{2}$ School of Mathematics, Statistics and Computer Science, University of KwaZulu-Natal, \\ Westville Campus, Private Bag X54001, Durban 4000, South Africa \\ ${ }^{3}$ Corresponding author
}

chiejinamonyei@gmail.com, adewumia@ukzn.ac.za

\begin{abstract}
The energy crisis of 2008 in South Africa, due to electricity demand surpassing supply and a depleted electricity reserve margin has exposed the need for more synergy between home energy management systems (HEMS) and supply side energy management systems (SSEMS). Demand side management (DSM) techniques have been investigated and proven to be viable means of regulating electricity demand from the consumer side. However, the viabilty of DSM is dependent on the participation of willing consumers. In this paper, a combined energy management system (CEMS) is proposed to provide a platform for incorporating the demands and constraints of consumers (time of dispatch, reduction of electricity costs etc.) and suppliers (reduced operations cost, reduced emissions etc.). The proposed CEMS utilizes dynamic pricing (DP) and a standard deviation biased genetic algorithm (SDBGA) in minimizing the DSM window to be allocated to the DSM loads of consumers based on the multi-objective constraints. The Medupi power plant which has been modelled to utilize carbon capture and sequestration (CCS) technology is used in carrying out the dispatch of the participating DSM loads (cloth washers, cloth dryers and dish washers) for 100000 random residential customers. Results show that in dispatch option 1 (in which the user is in control of the start time), a lower cost of electricity of ZAR 373218.40 is obtained compared to ZAR 416280.20 by dispatch option 2 (in which the utility selects dispatch time for participating DSM loads) for the consumers. However, dispatch option 2 achieves a better minimized DSM window (14.94 MW), lower operating cost (about 1.6\% lower than dispatch option 1), higher plant capacity utilization (87.92\% efficiency) and a more evenly distributed profile.

Keywords - demand side management, combined energy management system, home energy management system, supply side energy management system, standard deviation biased genetic algorithm
\end{abstract}
Highlights
$\checkmark$ Proposes a centralized energy management system for incorporating HEMS and SSEMS.
$\checkmark$ Evaluates DSM for 100000 random homes having cloth washers, cloth dryers and dish washers.
$\checkmark$ Uses a single DSM window to compare savings from dynamic pricing (DP) and time of use (TOU) pricing.
$\checkmark$ Compares supply and consumer side benefits for leaving the control of DSM load start time selection with either the utility or the consumers.

\section{Introduction}

Generally, an electricity network consists broadly of generation (supply) stations, transmission/distribution network and the utilization/consumers side. At the supply/generation side, the objective of the supply side energy management system (SSEMS) is to minimize operations and emissions cost [24]. The transmission line management system (TLMS) ensures that line ampacity limits are not exceeded. The ampacity limits for transmission lines could either be static thermal line ratings (STLR) or dynamic thermal line ratings (DTLR) [12]. At the utilization point, home energy management systems (HEMS) aim at reducing the electricity bills 
of homes (while improving their comfort) by smartly dispatching loads during periods of low electricity cost [5]. The overall grid operation thus aims at optimally scheduling generation and load dispatch to ensure that there is a balance betwen demand and supply while meeting the individual objectives of SSEMS, TLMS and HEMS.

Integrated energy systems (IES) promote the concept of a synergized and harmonized community of energy systems based on the bi-directional flow of information (data). This synergy in terms of operation and information flow improves system's efficiency [25]. The concept of IES is however at variance with the traditional electricity grid operation which isolates the individual operations of each management system. In creating a synergy of operations, IES also provide a platform for the exploitation of such concepts as demand side management (DSM) through price based demand response (DR) and direct load control (DLC). These initiatives become very important considering spiralling energy demand and the huge costs involved in power plant capacity expansion. For example, the energy crisis of South Africa which started in 2008 led to serious load shedding and blackouts across the country affecting homes and businesses [30, 33]. Depleted reserve margins due to long years of non-investment in building additional power plants to cater for growing electricity demand was blamed for the crisis. However, the huge costs involved in building power plants and the long time frame from conceptualization to eventual completion and synchronization of the power plant output with the grid [39] have seen power shortages, loadshedding and grid interruptions extending to 2015 [33]. Furthermore, the growing population and increasing industrial activities [50] mean that other alternatives besides increasing generation capacity be exploited to guarantee electricity availability and security.

A review of existing government policy via its Integrated Resource Plan (IRP) [14] shows no significant improvement in existing DSM capacity in the short to medium term. In the same vein, Eskom's participation in the DSM sector is centred around efficiency initiatives such as distribution of energy efficient compact fluorescent lamp (CFL) bulbs [15] with moderate investments in solar water heating [21], wind [20], concentrating solar power (CSP) [16] etc. According to [23, 22], Eskom plans to start decommissioning ageing power plants (Camden, Hendrina and Arnot) from 2021. While it is envisaged that ongoing construction works on Medupi, Kusile, Dedisa and Ingula power plants together with new coal independent power projects (IPP) would deliver an additional 8249 MW to the grid between 2017-2020 as shown in Table 1, the issue of delays due to technical constraints [17] cast huge doubts over Eskom's proposed commissioning plans. The need therefore arises for alternatives that will mitigate greatly the problems of blackouts and grid failures owing to demand exceeding supply.

Demand side management (DSM) techniques have been investigated and proven to be viable alternatives to regulating the consumption of electricity from the consumer side with applications from residential to industrial sectors [1, 34, 27, 29, 8, 2]. According to [46], the two techniques for DSM from the consumer side include energy efficiency improvement programs (insulation, sealing, solar water heating systems etc.) and demand response (DR) programs (price based and incentive based). While the energy efficiency improvement programs aim at increasing efficiency by reducing the amount of electricity required to accomplish similar tasks (with absence of supply side interference), the DR programs are initiated primarily by the supplier to influence consumer demand patterns. The home energy management systems (HEMS) [35, 45, 43, 26, 49, 7] are the backbone of DR program initiatives as they provide the platform for home owners to interact with their electrical appliances and their meters [42]. On the supply side, its management system (SSEMS) refers to actions taken to ensure that electricity is generated and supplied at lowered operating costs, reduced environmental emissions and optimal system reliability [28].

A review of available literature with particular focus on South Africa's electricity sector reveals that the operations of the HEMS and SSEMS have been largely independent of each other. In attempting to extend the focus area outside of South Africa, [28] argued on the need for the integration of HEMS (DSM) and SSEMS for a realistic power system planning. The need therefore exists for a platform that is capable of harmonizing the constraints of both the supply side and demand side with the aim of:

- Reducing consumer electricity bill through the application of dynamic pricing - HEMS objective

- Mitigating energy poverty by extending the usage of owned electrical appliances through reduced electricity bills. This is necessary since energy poverty is not only a function of ownership of electrical appliances but duration of use.

- Reducing operations and emissions cost of the supply side - SSEMS objective.

In doing so, the proposed platform must be capable of optimally scheduling DR loads (consumer controlled or utility controlled) in a DSM window (from generating capacity). This research work therefore contributes to existing DSM initiatives by:

(1) Extending the ongoing discussions on DSM initiatives by highlighting the need for synergy between HEMS and SSEMS and its benefits.

(2) Modelling and designing a centralized energy management system (CEMS) that accepts constraints and requirements from both the consumers and suppliers and optimally schedules DR loads for dispatch to meet the individual constraints. 


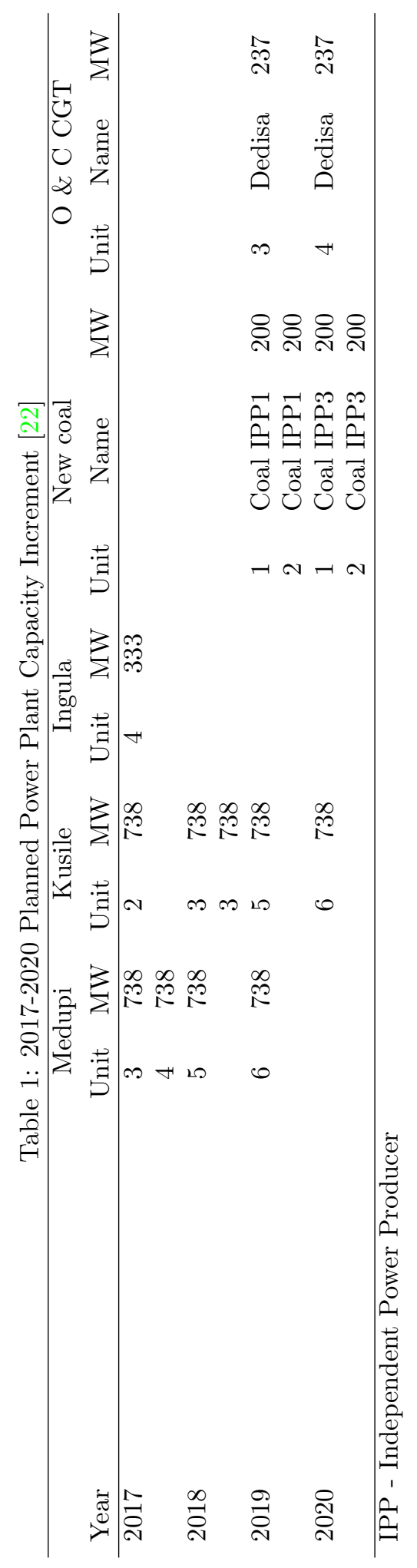


(3) Optimally scheduling a DSM window from the generating plant overall capacity within which DSM loads can be dispatched. The DSM window is a fraction of the power plant overall capacity within which DR loads are to be dispatched based on the user requirements (time flexibility in dispatching load).

In attempting to model and design the proposed CEMS, one hundred thousand random homes in South Africa within the Limpopo province are selected. Furthermore, three deferrable loads (washing machine, cloth dryer and dish washer) are selected per house with 3 possible time-dispatch classes. Home owners are lastly provided with a control to select the time-window (2 hours, 6 hours or 24 hours) within which dispatch of participating DDSM loads should be done. Dynamic pricing (DP) is used along with time of use (TOU) pricing for comparison. The power plant utilized in carrying out the dispatch of the participating DR loads is the Medupi power plant which has been modelled to utilize carbon capture and sequestration (CCS) technology. The dispatch of the participating DSM loads is done using a standard deviation biased genetic algorithm (SDBGA).

The rest of the paper is organized as follows. Section 2 presents a review of related works and a justification for this research; Section 3 presents the case study description while CEMS is briefly modelled in Section 4. The mathematical description of the problem, pricing method adopted and SDBGA is described in Section 5. The results obtained are discussed in Section 6 while policy implications of CEMS on the consumer and supplier are briefly presented in Section 7. The work is concluded in Section 8 while Section 9 presents the general applicability of CEMS.

\section{Related works}

An economic model for demand response with the objective of maximizing the customer utility with constraints by either the daily budget or daily consumption was developed by [36]. The economic model was designed to explain the consumer consumption change pattern. An energy management system (EMS) that targeted average income earners in sub-Saharan Africa (SSA) was developed by [41]. The proposed EMS was capable of maximizing available capacity of a residential solar based inverter by optimally scheduling competing loads. The rule set involved in the proposed EMS did not aim at maximizing user satisfaction. In advancing the EMS design proposed by [41], [40] proposed an EMS that was capable of controlling residential loads, maximizing user satisfaction and minimizing household electricity cost. The lack of 'smartness' in pre-paid meters (common in SSA), was addressed by [42], where a smart energy management system that acted as an interface between the meter and the consumer loads was proposed. A demand side distributed and secured energy commitment framework and operations for a power producer in a deregulated environment was proposed by [9] while [1] proposed a stochastic programming model using a multi-objective particle swarm optimization method for optimizing smart grid performance, minimizing operations costs and reducing emissions with renewable sources.

Further application of DSM was done by [47] for a cement plant with a $4.2 \%$ reduction in electricity cost and [29] for cost minimization of a water supply system. A comprehensive review on demand side tools was done by [46] while the challenges of integrating HEMS with residential demand-side aggregators was addressed by [10]. An exploration of available literature was carried out by [3] and incentive-based DR programs were considered to be the most suitable solutions to addressing the problem of growing per capita electricity consumption in Kuwait. For further reading on DSM and its applications, see [4, 31, 48, 6]. The contributions of preceding works notwithstanding, they have not been able to show the effect of DSM load control scheme (direct load control, (DLC) or consumer control) and dispatch window on energy poverty mitigation and DSM window minimization. This work extends research on DSM load dispatch by studying the effect of variable load control schemes (direct load control, (DLC) and consumer control) and dispatch window (duration within which participating DSM loads must be dispatched and completed) on the DSM load profile (DSM window minimization) and on energy poverty mitigation.

\section{$2.1 \quad$ Research motivation}

A justification for this research stems from the following:

- There has been a steady decline in electricity per capita for South African homes despite increasing generation (see [37]).

- Planned supply capacity expansion between 2017-2014 is over 5 times capacity loss and demand increase within the same period. According to [22], while $3516 \mathrm{MW}$ is expected to be lost due to the decommissioning of ageing plants between 2021 and 2024, over 19000 MW is expected to be added to the grid generation capacity between 2017 and 2024. This translates to a net increase of about $15484 \mathrm{MW}$. The expected addition to the grid capacity between 2017 and 2024 is over 5 times the capacity to be lost. Demand increase within 2017 and 2024 using the high (less energy intensive) forecast from [13] is about 
$55078 \mathrm{GWh}$. Assuming a $70 \%$ utilization (of net increase) at 35\% availability, this translates to a net production of about 131106 GWh between 2017 and 2024.

- Most of the homes in South Africa (based on [37]) are energy poor due to low electricity per capita that prevents extended usage of owned electrical appliances.

- According to [11], over $40 \%$ of global energy consumption comes from the residential and building sectors. This thus implies that households offer great potentials for DSM initiatives.

The computation of the electricity per capita (to show declining electricity consumption) for the nine provinces in South Africa on yearly (kWh/capita), monthly (kWh/capita), daily (kWh/capita) and hourly (Wh/capita) basis for 2007, 2011 and 2016 is shown in [37].

\section{Case study description}

\subsection{Consumer side problem description}

One hundred thousand residential homes are selected (for the simulation) across the Limpopo province, which is home to the Medupi power plant. Each selected home, $i$, is expected to possess at least a cloth washer, a cloth dryer and a dish washer. Each selected residential home is fitted with a HEMS and allows the home owner to:

(1) Select a class $\left(k_{i}\right)$. A class corresponds to a pre-defined dispatch period for the participating DSM loads (cloth washer, cloth dryer and dish washer). Table 2 provides further information regarding the dispatch time and slot for each class. Three classes are offered in this modelling exercise. Thus for example, a class one choice by house 1000 (i.e. $k_{1} 000=1$ ) corresponds to 75 minutes $(5$ slots) duration for the cloth washer, 105 minutes (7 slots) duration for the cloth dryer and 105 minutes $(7$ slots) duration for the dish washer. A slot is equivalent to 15 minutes duration.

(2) Initialize start time $\left(t_{i, j}^{\text {start }}\right)$ for each appliance $j$. A start time need not necessarily be the eventual dispatch time $\left(t_{i, j}^{\text {dispatch }}\right)$.

(3) Select a dispatch window $w_{i}$. A dispatch window is a period from the initialized start time $\left(t_{i, j}^{\text {start }}\right)$ within which the dispatch of a participating DSM load must be completed. Thus a dispatch window selection of 1 by house $1000\left(w_{1000}=1\right)$ means that the window within which a DSM load selected must be dispatched and dispatch completed is between $t_{i, j}^{\text {start }}$ and $t_{i, j}^{\text {start }}+2\left(\begin{array}{ll}8 & \text { slots }\end{array}\right)$.

\subsubsection{Justification for choice of Limpopo Province}

A justification for the choice of the Limpopo province stems from the fact that hourly electricity consumed per person (capita) as observed from [37] as at 2016 was about $107.38 \mathrm{Wh}$ which was among the lowest across the provinces. CEMS application is thus necessary to investigate its potential benefit in mitigating energy poverty among energy poor homes.

Table 2: Class description, its dispatch time and number of slots

\begin{tabular}{lcccc}
\hline Class & & Cloth washer & Cloth dryer & Dish washer \\
\hline \multirow{2}{*}{2} & mins & 75 & 105 & 105 \\
& slots & 5 & 7 & 7 \\
& mins & 60 & 75 & 75 \\
3 & slots & 4 & 5 & 5 \\
& mins & 30 & 45 & 60 \\
& slots & 2 & 3 & 4 \\
\hline
\end{tabular}

By definition,

$$
\begin{gathered}
1 \leq i \leq 100000 \\
1 \leq j \leq 3 \\
k_{i}=\{1,2,3\} \\
w_{i}=\{2,6,24\} \text { hours }
\end{gathered}
$$


If the daily cumulative energy demand for all DSM loads in any residential house $i$ is $E_{i}^{\text {energy }}$ and $P_{i}^{F P}$ and $P_{i}^{D P}$ are the daily fixed price cost (electricity cost using Eskom's TOU pricing) and daily dynamic price cost (electricity cost using dynamic pricing) of DSM loads (energy) for house $i$, then the HEMS aims at:

(1) Minimizing $P_{i}^{D P}$ such that $P_{i}^{D P} \leq P_{i}^{F P}$

(2) Optimally scheduling the dispatch time $t_{i, j}^{\text {dispatch }}$ of each appliance $j$ for house $i$. Where $t_{i, j}^{\text {dispatch }}$ is the final dispatch time of an appliance $j$ for house $i$ as evaluated by the SDBGA.

Thus,

$$
t_{i, j}^{\text {start }} \leq t_{i, j}^{\text {dispatch }}+t_{i, j}^{\text {duration }} \leq t_{i, j}^{\text {stop }}
$$

where $t_{i, j}^{\text {duration }}$ is the duration period for appliance $j$ and house $i$ as obtained from Table 2 .

$$
t_{i, j}^{\text {stop }}=t_{i, j}^{\text {start }}+w_{i} *
$$

Thus, the cost function associated with the HEMS is defined as

$$
Z_{H E M S}=\operatorname{minimize}\left(P_{i}^{D P}\right)
$$

Table 3 presents the power rating of the participating DSM loads for each residential house.

Table 3: Cloth washer, cloth dryer and dish washer statistics

\begin{tabular}{lccc}
\hline Equipment & Device Rating $(\mathrm{W})$ & Number per household & Total Power $(\mathrm{W})$ \\
\hline Cloth washer & 500 & 1 & 500 \\
Cloth dryer & 1000 & 1 & 1000 \\
Dish washer & 1200 & 1 & 1200 \\
\hline
\end{tabular}

\subsubsection{Justification for $k_{i}$ and $w_{i}$ pre-selection}

The pre-selected dispatch times for the cloth washer (30 mins., 60 mins. and 75 mins.), cloth dryer (45 mins., 75 mins. and 105 mins.) and dish washer (60 mins., 75 mins. and 105 mins.) mirror conventional use time and makes for ease in simulating their use. Also, the pre-defined windows $w_{i}$ are provided to offer the utility some flexibility in dispatch. While it is expected that a house that selects $w_{i}^{*}=8$ intends for $t_{i, j}^{\text {dispatch }}=t_{i, j}^{\text {start }}$, the inconvenience in $t_{i, j}^{\text {dispatch }}>t_{i, j}^{\text {start }}$ is expected to be compensated by reduced electricity bills.

\subsection{Supply side problem description}

In dispatching the participating loads, the Medupi power plant is modelled to utilize carbon capture and sequestration (CCS) technology. From the consumer side, two kinds of loads are easily deduced - base/bulk load and the DSM load. A DSM window is to be created within the operating profile of the power plant within which loads participating in DSM would be dispatched. Furthermore, dispatch of residential loads is to be done to ensure optimal power plant utilization and reduced operations costs. The SSEMS thus aims at:

(1) Minimizing the DSM window $C^{D S M}$ in the power plant operations profile within which the DSM loads can be dispatched. This leads to maximization of the base load capacity $C^{B L}$.

(2) Maximizing the utilization of the power plant capacity $U^{u t i l}$.

(3) Minimizing the power plant operations cost $F^{O P \operatorname{cost}}$.

(4) Minimizing the power plant emissions cost $F^{\text {Ecost }}$.

(5) Maximizing earnings $P_{i}^{D P}$ from each household.

The relationship between the power plants reserve capacity $\left(C^{\text {Reserve }}\right)$, base load capacity $\left(C^{B L}\right)$ and DSM capacity $\left(C^{D S M}\right)$ is shown in equation (8) while the operations cost of the power plant is computed as shown in equation (9).

$$
\begin{gathered}
C^{B L}+C^{D S M}+C^{\text {Reserve }}=C^{\text {Plant }} \\
F^{\text {OPcost }}=a+\left(b \times \varepsilon^{t}\right)
\end{gathered}
$$

where a and $\mathrm{b}$ are gotten from Table $4, \varepsilon^{t}$ is the loading factor (i.e. the fraction) of the power plant currently being utilized and $t$ is the slot being considered. In a 24-hour modelling window with 15 minutes interval, there are four slots per hour. This translates to 96 slots for 24 hours.

Assuming $Z_{S S E M S}$ to be the cost function associated with the supply side, then its description is shown subsequently.

$$
Z_{S S E M S}=\max \left(P^{D P}, U^{u t i l}\right)+\min \left(F^{O P \cos t}, F^{E \cos t}, C^{D S M}\right)
$$


Table 4: Modified Medupi Power Plant Modelling Parameters

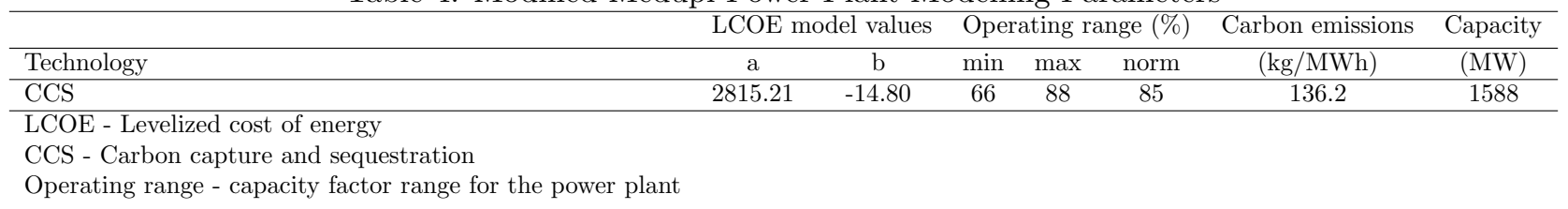

\subsubsection{Normalization of SSEMS associated parameters}

$Z_{S S E M S}$ is a non-linear function and cannot be resolved using exact solutions since its optimization cuts across parameters that are of varying units. For example, while $P^{D P}, F^{E c o s t}$ and $F^{O P \operatorname{cost}}$ are in ZAR, $U^{u t i l}$ is expressed as a percentage (\%) while $C^{D S M}$ is in $M W$. To resolve $Z_{S S E M S}$ therefore, all associated parameters are normalized. Table 5 presents the base values used in normalizing $P^{D P}, F^{E \operatorname{cost}}, F^{O P \operatorname{cost}}, C^{D S M}$ and $U^{u t i l}$. Thus, if $P_{\text {norm }}^{D P}, F_{\text {norm }}^{E c o s t}, F_{\text {norm }}^{O P \operatorname{cost}}, C_{\text {norm }}^{D S M}$ and $U_{\text {norm }}^{\text {util }}$ are the normalized values for $P^{D P}, F^{E c o s t}, F^{O P c o s t}, C^{D S M}$ and $U^{\text {util }}$, then $P_{\text {norm }}^{D P}=\frac{P^{D P}}{P_{\text {base }}^{D P}}, F_{\text {norm }}^{E c o s t}=\frac{F^{E c o s t}}{F_{\text {base }}^{E c o s t}}, F_{\text {norm }}^{O P \operatorname{cost}}=\frac{F^{O P \text { cost }}}{F_{\text {base }}^{O P \text { cost }}}, C_{\text {norm }}^{D S M}=\frac{C^{D S M}}{C_{\text {base }}^{D S M}}$ and $U_{\text {norm }}^{\text {util }}=\frac{U^{\text {util }}}{U_{\text {base }}^{\text {utiv }}}$.

\subsection{DSM load dispatch options}

In dispatching the participating DSM loads (cloth washer, cloth dryer and dishwasher) for the 100000 houses in the Limpopo province, two dispatch options are modelled as follows:

\subsubsection{Dispatch option 1}

For dispatch option 1 , the customers $i$ are in charge of selecting $k_{i}, w_{i}$ and their intended start time $\left(t_{i, j}^{\text {start }}\right)$ for each DSM $j$ load. In this option, the utility (Eskom) is only able to influence final dispatch time $\left(t_{i, j}^{\text {dispatch }}\right)$ of the load $j$ such that $t_{i, j}^{\text {start }} \leq t_{i, j}^{\text {dispatch }} \leq t_{i, j}^{\prime}$. The flexibility of the dispatch time denoted as $\left.f_{i, j}^{\text {option } 1}\right|_{t_{i, j}^{\text {start }}}$ is defined as:

$$
\left.f_{i, j}^{\text {Option } 1}\right|_{t_{i, j}^{\text {start }}}=\frac{t_{i, j}^{\prime}-t_{i, j}^{\text {start }}}{t_{i, j}^{\text {start }}}
$$

However, $t_{i, j}^{\prime}=t_{i, j}^{\text {stop }}-t_{i, j}^{\text {duration }}$ and $t_{i, j}^{\text {stop }}=t_{i, j}^{\text {start }}+4 w_{i} *, \Rightarrow t_{i, j}^{\prime}=t_{i, j}^{\text {start }}+4 w_{i} *-t_{i, j}^{\text {duration }}$ Hence,

$$
\left.f_{i, j}^{\text {Option } 1}\right|_{t_{i, j}^{\text {start }}}=\frac{4 w_{i} *-t_{i, j}^{\text {duration }}}{t_{i, j}^{\text {start }}}
$$

The end limits (minimum and maximum) possible selection of $w_{i}$ are 2 hours ( 8 slots) and 24 hours (96 slots) respectively.

If $w_{i} *=8$, then $\left.f_{i, j}^{O p t i o n} 1\right|_{t_{i, j}^{\text {start }}}=\frac{8-t_{i, j}^{\text {duration }}}{t_{i, j}^{\text {start }}}$ and if $w_{i} *=96$, then $\left.f_{i, j}^{O p \operatorname{option} 1}\right|_{t_{i, j}^{\text {start }}}=\frac{96-t_{i, j}^{\text {duration }}}{t_{i, j}^{\text {start }}}$.

The constraint on $f_{i, j}^{O p t i o n} 1$ is given as:

$$
\frac{8-t_{i, j}^{\text {duration }}}{t_{i, j}^{\text {start }}} \leq\left. f_{i, j}^{\text {Option } 1}\right|_{t_{i, j}^{\text {start }}} \leq \frac{96-t_{i, j}^{\text {duration }}}{t_{i, j}^{\text {start }}}
$$

With the operating range of $\left.f_{i, j}^{O p t i o n} 1\right|_{t_{i, j}^{\text {start }}}$ given as $\frac{96-8}{t_{i, j}^{\text {start }}}=\frac{88}{t_{i, j}^{\text {start }}}$

The computation of $\left.f_{i, j}^{O p t i o n} 1\right|_{t_{i, j}^{\text {start }}}$ is to provide an insight into how much choice the proposed standard deviation biased genetic algorithm (SDBGA) has in optimally selecting $t_{i, j}^{\text {dispatch }}$ under the simulated options.

\subsubsection{Dispatch option 2}

In this option, the choice of selection of $t_{i, j}^{d i s p t c h}$ is entirely under the control of the utility, i.e. the participating DSM loads are under direct load control (DLC). Hence, under dispatch Option $2, w_{i}=3$ i.e. $w_{i} *=96$. However, the consumer selects $k_{i}$. By definition, under this option, $t_{i, j}^{\text {start }}=1, t_{i, j}^{\text {stop }}=96$ and $t_{i, j}^{i}=96-t_{i, j}^{\text {duration }}$.

$\left.\Rightarrow f_{i, j}^{\text {Option } 2}\right|_{t_{i, j}^{\text {start }}}=4 w_{i} *-t_{i, j}^{\text {duration }}$. Thus, the operating range of $\left.f_{i, j}^{\text {Option } 2}\right|_{t_{i, j}^{\text {start }}}$ is $96-t_{i, j}^{\text {duration }}$. Figure 1 presents the time-line progression of the various time instances $\left(t^{\text {start }} i, j, \quad t_{i, j}^{\prime}, \quad t_{i, j}^{\text {final }}, \quad t_{i, j}^{\text {duration }}\right.$ and $\left.t_{i, j}^{\text {stop }}\right)$. 


\subsection{Justification for $C^{D S M}$ window}

As posited by [28], the integration of DSM and SSEMS is necessary for realistic system planning. Pre-selecting the DSM window $C^{D S M}$ within which the participating DSM loads are to be dispatched provides the utility with advanced information for optimal system operation. Furthermore, the utility in pre-selecting a dispatch window $C^{D S M}$ is able to evaluate ahead of time, the optimal generation scheduling configuration of its generators that will achieve its objectives in terms of reduced $F^{\text {Ecost }}$ and $F^{O P \text { cost }}$ and prevent over-sizing of spinning reserves. However, in scheduling $C^{D S M}$, great care is taken not to under-size the window to prevent utilizing the generators beyond their normal operating range.

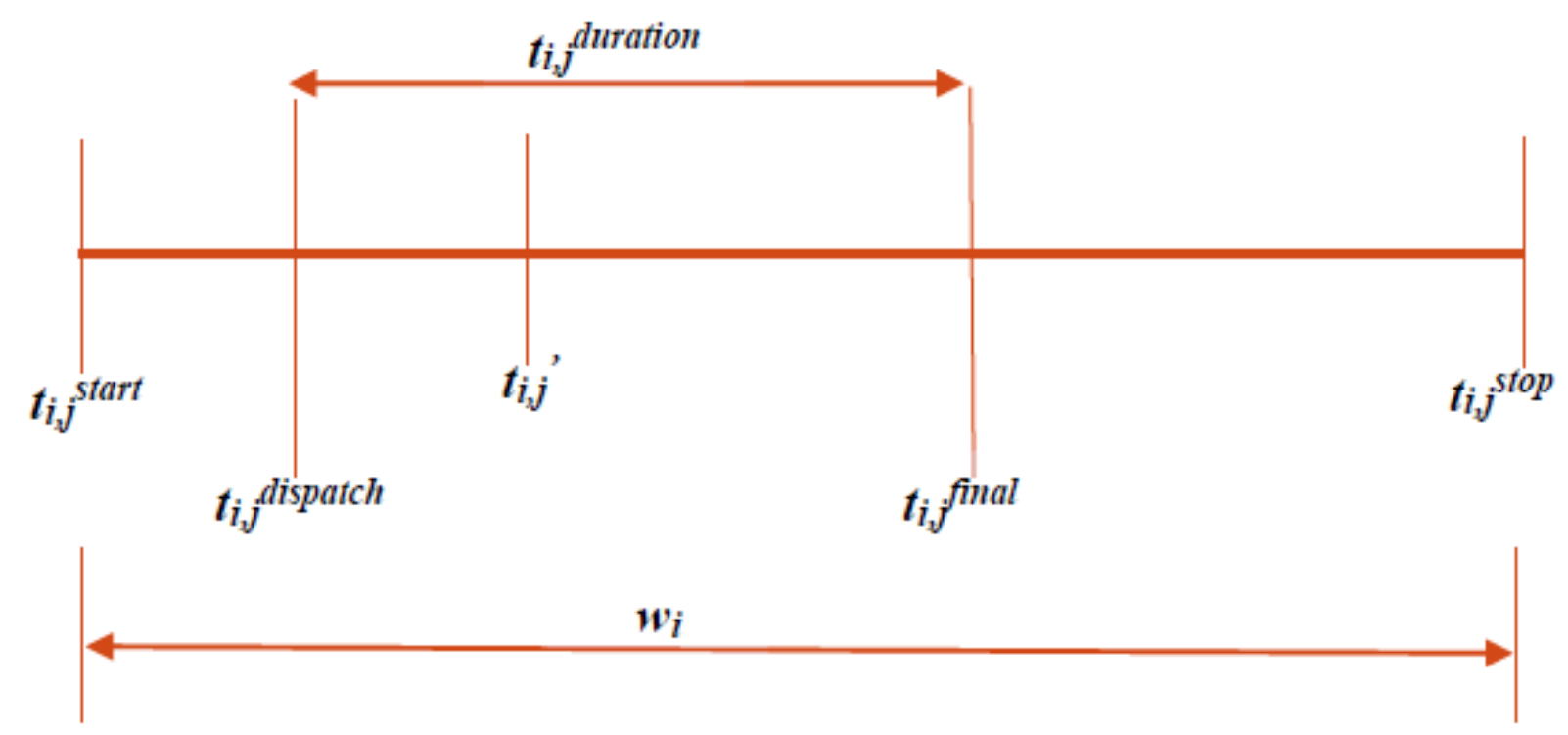

Figure 1: A typical time progression and execution window for DSM loads.

\section{CEMS modelling}

The complexity presented by the multi-objective and multi-dimensional problem is depicted in Figure 2 where the links and connections between the proposed CEMS, HEMS and SSEMS are properly shown. Furthermore, the ensuing conflicts that may arise from the individual objectives of HEMS and SSEMS are seen. For example, while HEMS aims to minimize $P_{i}^{D P}$, SSEMS aims at maximizing $P_{i}^{D P}$. The resolution of this resulting conflict is explained subsequently.

\subsection{HEMS and SSEMS conflict matrix}

The harmonization of the household and supply requirements does reveal some conflicts. The conflict matrix shown in Table 6 presents the five major conflict spots between the HEMS and SSEMS working requirements. For example, conflict $C_{1,2}$ which is the conflict between the SSEMS constraint 1 and HEMS constraint 2 shows that in trying to minimize $C^{D S M}$ by the SSEMS, the possibility of failing to dispatch household loads within their pre-determined window by the HEMS is possible due to reduced $C^{D S M}$. Also, conflict $C_{2,2}$ describes the possibility of low utilization of power plant capacity by the SSEMS due to low dispatch of residential DSM loads within certain periods owing to external constraints like line ampacity limits. The conflict $C_{4,1}$ denotes the conflict that arises in trying to reduce emissions cost by the SSEMS. The unintended consequence might be a higher cost of electricity $P^{D P}$ for households during such periods. Similarly, conflict $C_{4,2}$ arises when SSEMS in trying to reduce $F^{E \text { cost }}$ selects $t_{i, j}^{\text {dispatch }}$ under dispatch option 1 that is outside the range $\left(t_{i, j}^{\text {start }}, t_{i, j}^{\text {start }}+w_{i}\right)$. Conflict $C_{5,1}$ denotes a direct conflict between SSEMS and HEMS in optimizing $P_{i}^{D P}$. While SSEMS strives at maximizing its value, HEMS aims at minimizing it. A platform is thus needed that is capable of addressing these constraints and optimally scheduling $t_{i, j}^{\text {dispatch }}$ of consumer DSM loads within the HEMS and SSEMS defined limits. 


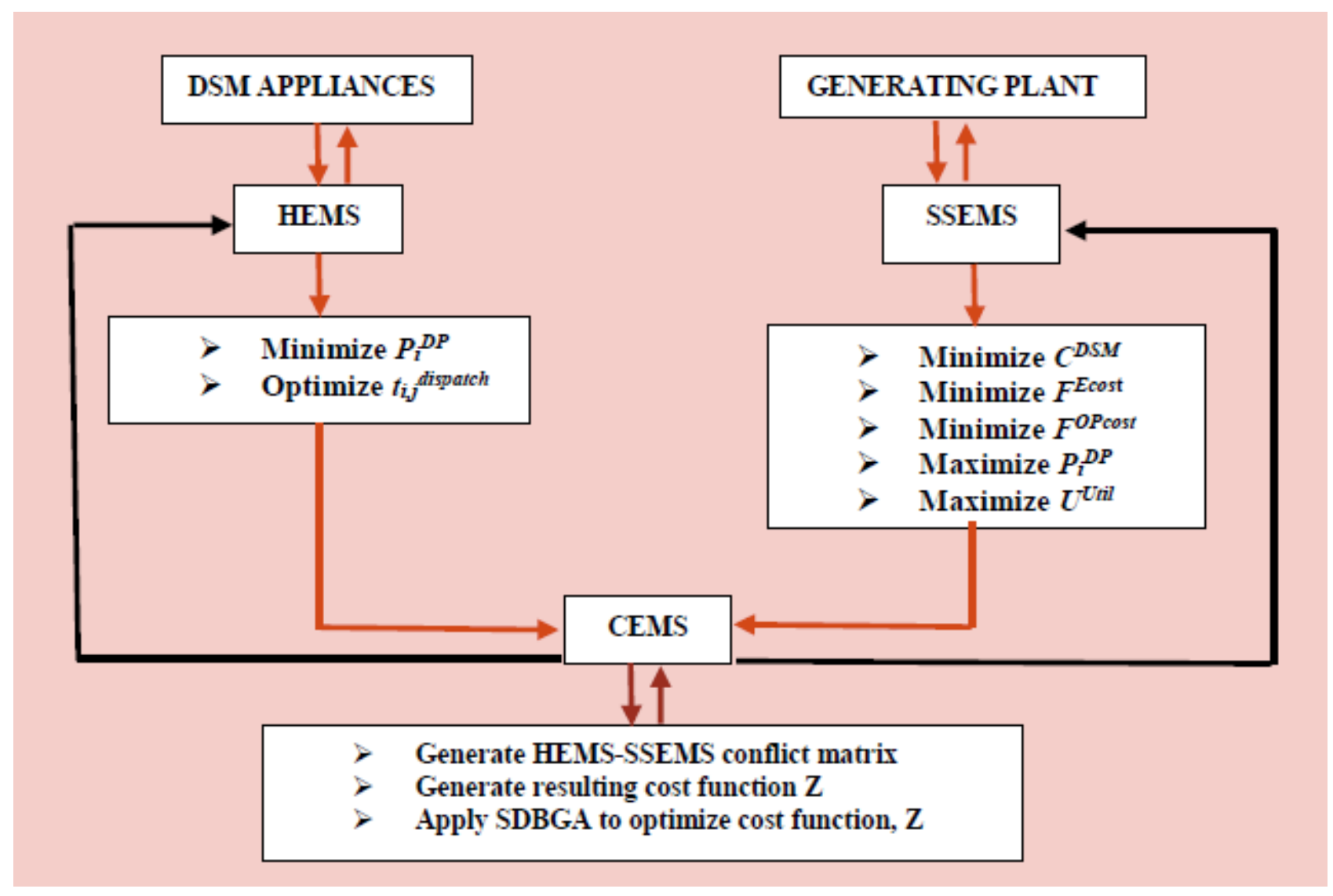

Figure 2: Proposed CEMS infrastructure incorporating the HEMS and SSEMS.

\section{$5 \quad$ Mathematical modelling}

This section presents the mathematical description for HEMS, SSEMS and SDBGA including discussions on the pricing models adopted and power plant utilized and their justification.

\subsection{HEMS constraints modelling and description}

Three classes $k_{i}$ as shown in Table 2 and equation (3) are adopted in this research. A selection $k_{100}=2$ implies that class 2 has been selected by house 100. A consequence of this thus implies that the dispatch time of the washing machine, cloth dryer and dish washer is 75 minutes ( 5 slots), 105 minutes ( 7 slots) and 105 minutes (7 slots) respectively. An initial start time $t_{i, j}^{\text {start }}$ and dispatch window $w_{i}$ is selected by the user for every appliance (under dispatch option 1).

Given $t_{i, j}^{\text {start }}, k_{i}$ and $w_{i}$, a dispatch time $t_{i, j}^{\text {dispatch }}$ is sought such that

$$
t_{i, j}^{\text {start }} \leq t_{i, j}^{\text {dispatch }} \leq t_{i, j}^{\prime}
$$

where $t_{i, j}^{\prime}$ is the final time a DSM device $j$ for house $i$ must be dispatched to meet with the user predetermined window $w_{i}$ selection. By dispatch, we mean "turned on."

Thus,

$$
t_{i, j}^{\prime}=t_{i, j}^{\text {stop }}-t_{i, j}^{\text {duration }}
$$

The associated cost of dispatch which is evaluated using both the time of use (TOU) pricing and dynamic pricing (DP) for comparison purposes is computed as follows: Let $F P^{t}$ be the TOU price and $D P^{t}$ the dynamic price, then

$$
\begin{aligned}
& P_{i}^{D P}=\sum\left(D P^{t} * E_{i, j, t}^{\text {energy }}\right), t=t_{i, j}^{\text {dispatch }}: t_{i, j}^{\text {final }}, i=1: 100000, j=1: 3 \\
& P_{i}^{F P}=\sum\left(F P^{t} * E_{i, j, t}^{\text {energy }}\right), t=t_{i, j}^{\text {dispatch }}: t_{i, j}^{\text {final }}, i=1: 100000, j=1: 3
\end{aligned}
$$




\subsection{SSEMS constraints modelling and description}

Figure 3 presents the typical profile of the Medupi power plant showing the base load $\left(C^{B L}\right), \mathrm{DSM}\left(C^{D S M}\right)$ and reserve allocations $\left(C^{\text {Reserve }}\right)$. Assuming a maximum operating range (capacity factor) of $88 \%$ (as obtained from Table 4), the following is obtained:

$$
\begin{gathered}
C^{D S M}+C^{B L}=1397.44 M W \\
C^{\text {Reserve }}=190.56 \mathrm{MW}
\end{gathered}
$$

The utilization cost $U^{u t i l}$ is applied to utilization of the Medupi power plant capacity below $70 \%$ for any time $t$. This is necessary to prevent the build-up of peaks unnecessarily thus allowing for a evenly distributed dispatch profile. Thus, if $U_{t}^{u t i l} \geq 70 \%$, then $U_{t}^{u t i l}=0$, else $U_{t}^{u t i l}=u t i l_{\text {cost }}(t)$.

$$
U^{u t i l}=\sum_{t=1}^{96} U_{t}^{u t i l}
$$

The emissions cost $F^{E c o s t}$ is computed based on the $\mathrm{CO}_{2}$ emissions equivalent $\left(\mathrm{kgCO} \mathrm{O}_{2}\right)$ for energy (electricity) produced and consumed (MWh). Thus,

$$
F^{E c o s t}=\sum_{t=1}^{96}\left(E m i_{t} \times \sum_{i, j}\left(E_{t}^{\text {energy }}\right) \times b_{1} \times b_{2}\right)
$$

where $b_{1}$ is the conversion factor to ZAR and $b_{2}$ is the conversion factor of $E_{t}^{\text {energy }}$ from $M W$ to $M W h$. F $F^{E c o s t}$ is computed as shown in [32]. To convert to ZAR, prevailing exchange rate from [44] was used. SSEMS thus seeks to achieve an optimum operating point on its constraint wheel as shown in Figure 4 that guarantees load dispatch at minimum costs (environment, operations) and maximized income and generator utilization. Figure 4 presents the normalized constraint wheel for the SSEMS with each normalized factor having a range of possible selection. SSEMS thus selects points for each normalized factor that gives it the best operating conditions.

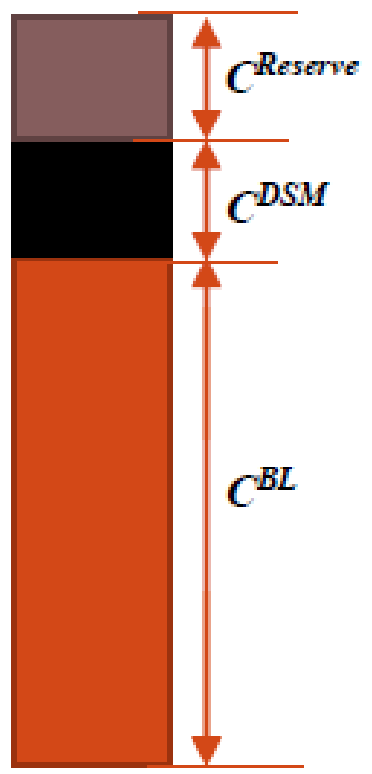

Figure 3: A typical capacity profile of the Medupi power plant. 


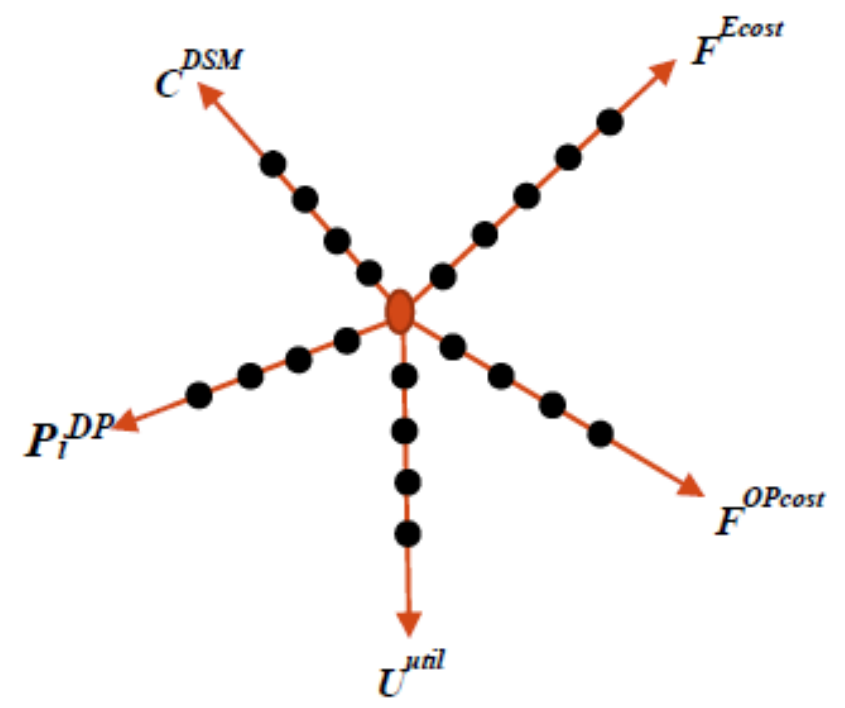

Figure 4: SSEMS constraint wheel.

\subsection{Price modelling}

Two pricing schemes have been adopted for this model and they are the exiting Eskom TOU pricing scheme and a dynamic pricing scheme.

\subsubsection{Time of use pricing}

The existing TOU pricing scheme assumes a flat rate price of $1.25 / k W h$ for off-peak periods with a $20 \%$ increment during 6am - 8am and 6pm - 8pm. The selected Eskom TOU pricing scheme is for a household whose monthly electricity consumption is less than $600 \mathrm{kWh}$. Weekends and weekdays have been assumed to have the same profile. The sample TOU dispatch profile for a day is shown in Figure 5.

\subsubsection{Dynamic pricing}

The computation of the dynamic price $D P^{t}$ follows the time of use (TOU) pricing being used by Eskom. As seen in Figure 5, the daily average dynamic price is equivalent to Eskom's TOU pricing (excluding the peak periods). Given $F P^{t}$ as the real time TOU pricing electricity spot price, then $\frac{1}{24} \sum_{t=1}^{t=24}\left(D P^{t}\right)=\overline{F P^{t}}$.

\subsection{Motivation for dynamic pricing model selected}

The TOU pricing scheme is adopted by Eskom to shift demand from peak periods to off-peak periods in order to prevent system collapse due to demand exceeding supply. In doing so, peak demand reduction is a motivation. However, the proposed dynamic pricing aims at:

- Improving the flexibility of the grid by offering the utility greater control of the electricity network. This is mostly the aim of dispatch option 2 in which the participating DSM loads are under DLC by the utility.

- Reducing electricity bills of consumers. The adoption of real time pricing guarantees the home-owners a reduction in their electricity bills over TOU pricing without altering their comfort level. In doing this, home-owners are able to save money that could be used in extending usage of electrical appliances.

- Reducing grid expansion investments. With the adoption of dynamic pricing and the subsequent control the utility has over the dispatch of participating DSM loads, the over-sizing of spinning reserves would be reduced since the utility can almost adequately predict the behaviour of the grid and optimize its overall operations. 
TOU versus Dynamic pricing plot

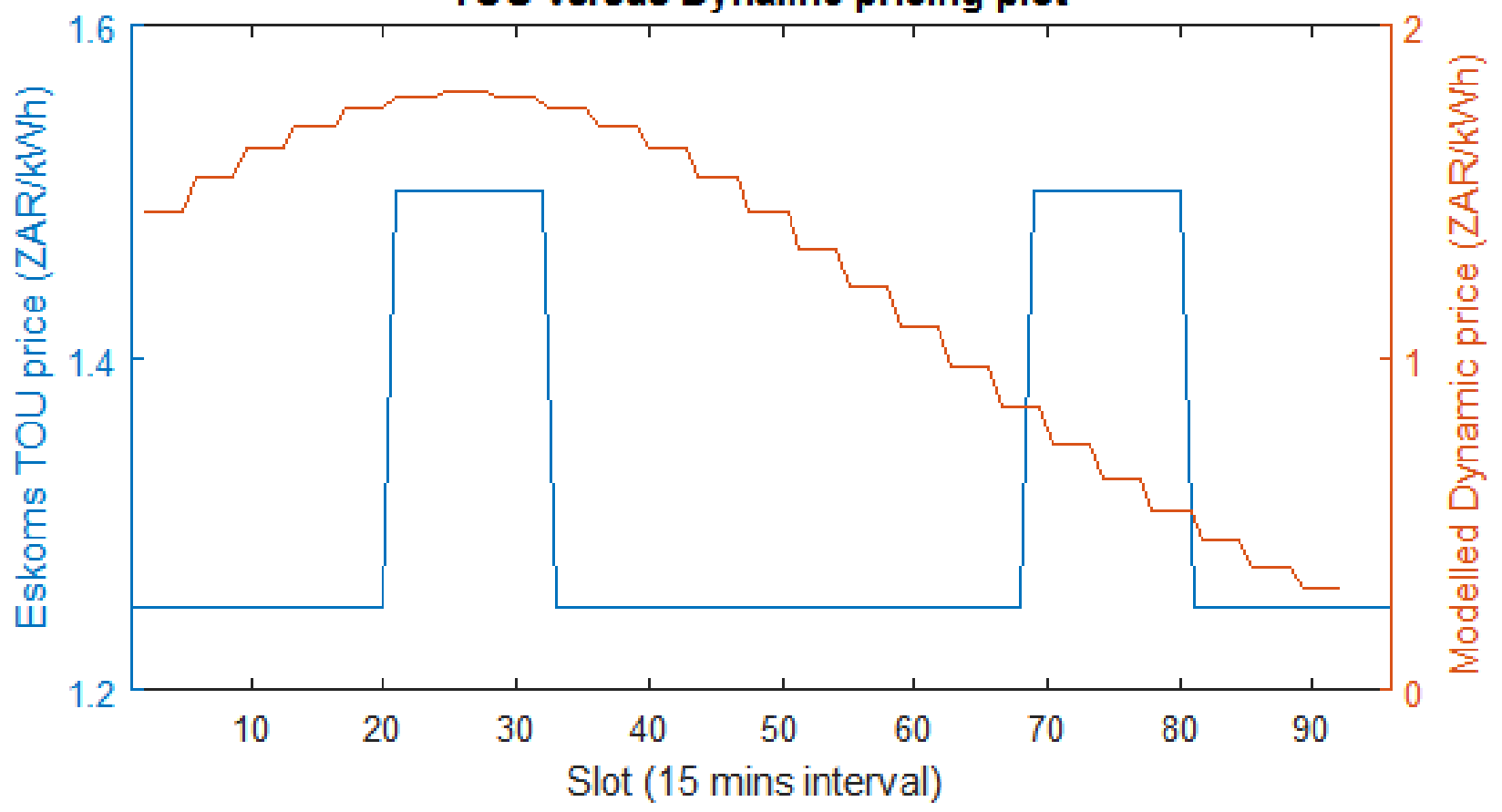

Figure 5: TOU pricing and dynamic pricing profiles.

\subsection{SDBGA modelling}

The proposed genetic algorithm (SDBGA) is a variant of MMIGA used in [42]. In differing from MMIGA, SDBGA computes the standard deviation of a generation matrix and selects the population with the highest spread. The notion behind this idea is to select the allocation that offers more spread in allocation of DSM loads dispatch time. This is to prevent the build up of multiple peaks.

\subsubsection{Population initialization}

$p o p_{v}^{1}$ for start times, $p o p_{v}^{2}$ for class selection, $p o p_{v}^{3}$ for window selection and $p o p_{v}^{4}$ for final dispatch time are generated as follows:

$$
\begin{gathered}
\operatorname{pop}_{v}^{1}=\left\{t_{1,1}^{\text {start }}, t_{1,2}^{\text {start }}, t_{1,3}^{\text {start }}, t_{2,1}^{\text {start }}, t_{2,2}^{\text {start }}, t_{2,3}^{\text {start }}, t_{3,1}^{\text {start }}, t_{3,2}^{\text {start }}, t_{3,3}^{\text {start }}, \ldots, t_{100000,1}^{\text {start }}, t_{100000,2}^{\text {start }}, t_{100000,3}^{\text {start }}\right\} \\
\operatorname{pop}_{v}^{2}=\left\{k_{1}, k_{2}, k_{3}, k_{4}, \ldots, k_{100000}\right\} \\
\operatorname{pop}_{v}^{3}=\left\{w_{1}^{*}, w_{2}^{*}, w_{3}^{*}, w_{4}^{*}, \ldots, w_{100000}^{*}\right\}
\end{gathered}
$$

$\operatorname{pop}_{v}^{4}=\left\{t_{1,1}^{\text {dispatch }}, t_{1,2}^{\text {dispatch }}, t_{1,3}^{\text {dispatch }}, t_{2,1}^{\text {dispatch }}, t_{2,2}^{\text {dispatch }}, t_{2,3}^{\text {dispatch }}, t_{3,1}^{\text {dispatch }}, t_{3,2}^{\text {dispatch }}, t_{3,3}^{\text {dispatch }}, \ldots, t_{100000,1}^{\text {dispatch }}, t_{100000,2}^{\text {dispatch }}, t_{100000,3}^{\text {dispatch }}\right\}$

The selection of $t_{i, j}^{\text {start }}$ and $w_{i}^{*}$ is either by the consumer (dispatch option 1) or the utility (dispatch option 2 ) while $k_{i}$ selection is solely by the consumer. This then implies that $\eta\left(p o p_{v}^{1}\right)=\eta\left(p o p_{v}^{4}\right)=300000$ and $\eta\left(\right.$ pop $\left._{v}^{2}\right)=\eta\left(\right.$ pop $\left._{v}^{3}\right)=100000$. Furthermore, $t_{i, j}^{\text {final }}=t_{i, j}^{\text {start }}+w_{i}^{*}-1$ (for dispatch option 1 ) and $t_{i, j}^{\text {final }}=96$ (for dispatch option 2). The incorporation of -1 is to compensate for start position and prevent over-float. Three population matrices $\left(\right.$ pop $\left._{v}^{4-x}, x=\{1,2,3\}\right)$ with dimensions $\operatorname{dim}_{1} \times \operatorname{dim}_{2}\left(\operatorname{dim}_{1}=\right.$ number of rows ornumber of houses and $\operatorname{dim}_{2}=$ number of slots) are also initialized to zero as shown in Figure 6. pop $v_{v}^{4-x}$ represents the matrix for $t_{i, j}^{\text {dispatch }}$ such that $\operatorname{pop}_{v}^{4-1}$ collects $t_{i, 1}^{\text {dispatch }}$ values, $p o p_{v}^{4-2}$ collects $t_{i, 2}^{\text {dispatch }}$ values while $p o p_{v}^{4-3}$ collects $t_{i, 3}^{\text {dispatch }}$ values. 


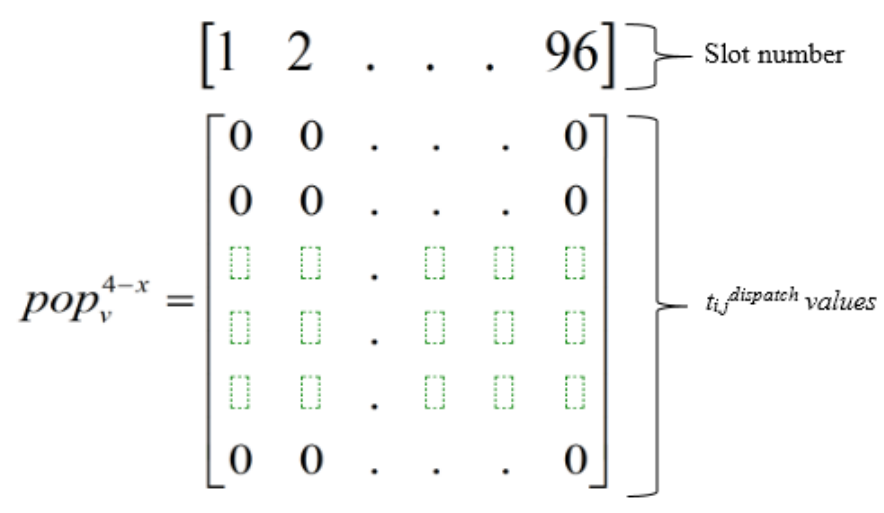

Figure 6: $\operatorname{pop}_{v}^{4-x}$ initialization description.

\subsection{2 $p o p_{v}^{4-x}$ filling}

The filling of $\operatorname{pop}_{v}^{4-x}$ is done based on the $t_{i, j}^{\text {dispatch }}$ stochastically evaluated for each household such that $t_{i, j}^{\text {start }} \leq$ $t_{i, j}^{\text {dispatch }} \leq t_{i, j}^{\prime}$. Let $\operatorname{pop}_{v}^{1}=\{2,5,5,1,1,1, \ldots, 3,3,88\}, \operatorname{pop}_{v}^{2}=\{1,1, \ldots, 3\}$ and $\operatorname{pop}_{v}^{3}=\{8,96, \ldots, 8\}$ be the associated statistics for houses 1,2 and 100000. This implies that houses 1 and 100000 are under the dispatch option 1 while house 2 is under the dispatch option 2. The description for the houses is as follows:

- House 1: $t_{1,1 / 2 / 3}^{\text {start }}=\{2,5,5\}, t_{1,1 / 2 / 3}^{\text {duration }}=\{5,7,7\}$ while $t_{1,1 / 2 / 3}^{\text {final }}=\{9,12,12\}$. All values are in slots. The range of the dispatch value for the DSM loads $j$ for house 1 is given to be $\{2,5,5\} \leq\left\{t_{1,1}^{\text {dispatch }}, t_{1,2}^{\text {dispatch }}, t_{1,3}^{\text {dispatch }}\right\} \leq$ $\{5,6,6\}$. The implication of this is that $2 \leq t_{1,1}^{\text {dispatch }} \leq 5,5 \leq t_{1,2}^{\text {dispatch }} \leq 6$ and $5 \leq t_{1,3}^{\text {dispatch }} \leq 6$.

- House $2: t_{2,1 / 2 / 3}^{\text {start }}=\{1,1,1\}, t_{2,1 / 2 / 3}^{\text {duration }}=\{5,7,7\}$ while $t_{2,1 / 2 / 3}^{\text {final }}=\{96,96,96\}$. All values are in slots. The range of the dispatch value for the DSM loads $j$ for house 2 is given to be $\{1,1,1\} \leq\left\{t_{2,1}^{\text {dispatch }}, t_{2,2}^{\text {dispatch }}, t_{2,3}^{\text {dispatch }}\right\} \leq$ $\{92,90,90\}$. The implication of this is that $1 \leq t_{2,1}^{\text {dispatch }} \leq 92,1 \leq t_{2,2}^{\text {dispatch }} \leq 90$ and $1 \leq t_{2,3}^{\text {dispatch }} \leq 90$.

- House 100000: $t_{100000,1 / 2 / 3}^{\text {start }}=\{3,3,88\}, t_{100000,1 / 2 / 3}^{\text {duration }}=\{2,3,4\}$ while $t_{100000,1 / 2 / 3}^{\text {final }}=\{10,10,95\}$. All values are in slots. The range of the dispatch value for the DSM loads $j$ for house 100000 is given to be $\{3,3,88\} \leq\left\{t_{100000,1}^{\text {dispatch }}, t_{100000,2}^{\text {dispatch }}, t_{100000,3}^{\text {dispatch }}\right\} \leq\{9,9,92\}$. The implication of this is that $3 \leq t_{100000,1}^{\text {dispatch }} \leq 9$, $3 \leq t_{100000,2}^{\text {dispatch }} \leq 9$ and $88 \leq t_{100000,3}^{\text {dispatch }} \leq 92$.

In filling pop $_{v}^{4-x}$, SDBGA aims at varying $t_{i, j}^{\text {dispatch }}$ within its minimum $\left(\underline{t_{i, j}^{\text {dispatch }}}\right)$ and maximum $\left(\overline{t_{i, j}^{\text {dispatch }}}\right)$ limits to ahieve the objectives of HEMS and SSEMS.

\subsection{3 $\operatorname{pop}_{v}^{4-x}$ initialization}

An initial allocation of $t_{i, j}^{\text {dispatch }}$ is made for all houses $i$ and load $j$ in $p o p_{v}^{4-x}$. The values randomly generated for $t_{i, j}^{\text {dispatch }}$ are always constrained by $t_{i, j}^{\text {start }} \leq t_{i, j}^{\text {dispatch }} \leq t_{i, j}^{\prime}\left(\underline{t_{i, j}^{\text {dispatch }}}=t_{i, j}^{\text {start }}\right.$ and $\left.\overline{t_{i, j}^{\text {dispatch }}}=t_{i, j}^{\prime}\right)$. In filling $\operatorname{pop}_{v}^{4-x}$ with $t_{i, j}^{\text {dispatch }}$ values, the range $\left\{t^{\text {dispatch }} i, j, t_{i, j}^{\text {dispatch }}+t_{i, j}^{\text {duration }}-1\right\}$ is initialized to 1 . Figures 7,8 and 9 present the initialization of $p o p_{v}^{4-x}$ for houses 1, 2 and 100000. It is observed from Figure 7 that for house 1 in $\operatorname{pop}_{v}^{4-1}$, slots $3-7$ are initialized to 1 , similarly, for house 2 in $p o p_{v}^{4-1}$, slots $60-64$ are initialized to 1 while for house 100000 in $p o p_{v}^{4-1}$, slots $4-5$ are initialized to 1 . The same rule is used in filling $p o p_{v}^{4-2}$ and $p o p_{v}^{4-3}$ based on each house's description given in section 5.5.2.

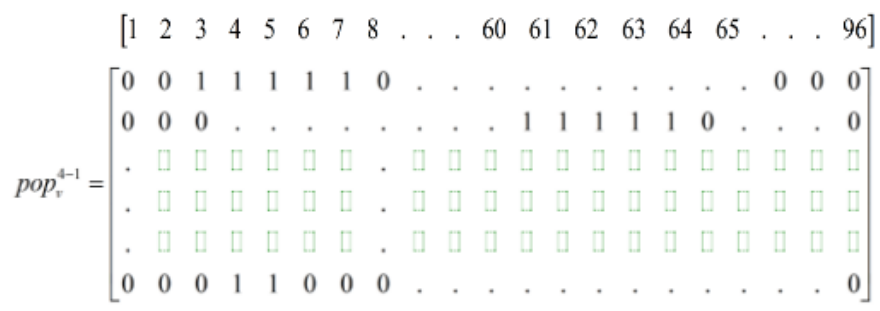

Figure 7: $p o p_{v}^{4-1}$ filling. 


\subsection{4 $t_{i, j}^{\text {dispatch }}$ variation}

For each filling of $p o p_{v}^{4-x}, E_{p o w e r}^{4-x}$ is computed. $E_{v}^{4-x}$ is the cumulative column sum of power in $p o p_{v}^{4-x}$. In generating $E_{\text {power }}^{4-x}$, pop $_{v}^{4-x}$ is multiplied by its respective power value. From Table $3, x=1 \longrightarrow$ power value is $500 \mathrm{~W}$. Similarly, $x=2 \longrightarrow$ power value is $1000 \mathrm{~W}$ while $x=3 \longrightarrow$ power value is $1200 \mathrm{~W}$. Thus, $E_{v}^{4-x}=\left\{e_{1}^{x}, e_{2}^{x}, \ldots, e_{96}^{x}\right\}$ where $e_{u}^{x}=\sum_{u=1}^{96} \operatorname{pop}_{v}^{4-x}(1: 100000, u)$. The generation of $E_{\text {power }}^{4-x}$ enables us to identify peak points and under-utilization points. These points are then isolated and used in varying $t_{i, j}^{\text {dispatch }}$. However, in the event that the constraints placed on $t_{i, j}^{\text {dispatch }}$ prevent it from being dispatched to points of under-utilization, then it is randomly computed using its constraints $-\underline{t_{i, j}^{\text {dispatch }}}$ for minimum and $\overline{t_{i, j}^{\text {dispatch }}}$ for maximum to be round $\left(\right.$ randi $\left.\times\left(\overline{t_{i, j}^{\text {dispatch }}} t_{i, j}^{\text {dispatch }}\right)+t_{i, j}^{\text {dispatch }}\right)$ where round is a function that converts any floating value to the nearest integer and $0<$ randi $<1$.

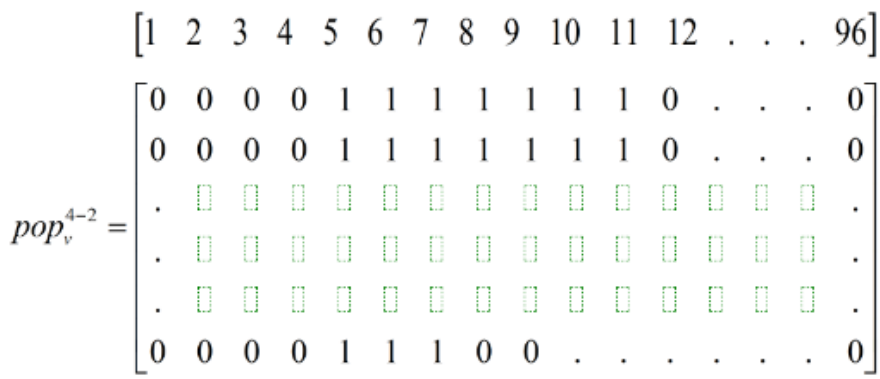

Figure 8: $p o p_{v}^{4-2}$ filling.

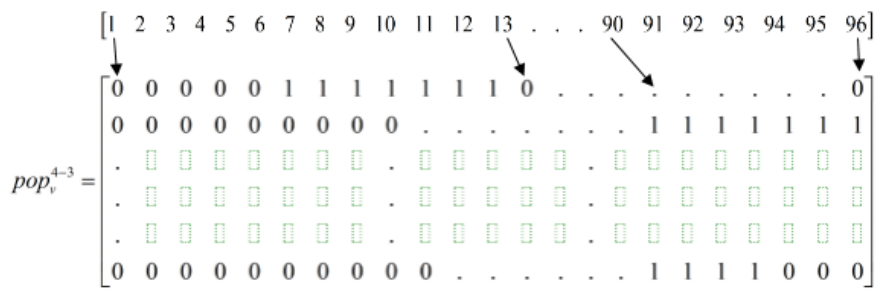

Figure 9: $p o p_{v}^{4-3}$ filling.

\subsubsection{Cost computation and optimal solution selection}

For each run of $p o p_{v}^{4-x}, P_{i}^{D P}, P_{i}^{F P}, F^{O P \operatorname{cost}}, F^{E c o s t}, U^{u t i l}, C^{D S M}$ and standard deviation $\left(s d_{v}\right)$ is computed. Furthermore, the cost, $Z_{v}$ associated with each population is calculated and used in ranking each solution. Selection of optimum solution, $S_{\text {gen }}^{\text {optimum }}$ is done as follows:

Given any op $_{1}^{4-x}$ and op $_{2}^{4-x}$ as the best population matrices per generation, gen, with standard deviations, $s d_{1}$ and $s d_{2}$, if $\left|Z_{1}-Z_{2}\right| \leq 1 \%$ of $\left|Z_{1}+Z_{2}\right|$ and $s d_{1}<s d_{2}$, then $S_{\text {gen }}^{\text {optimum }}=$ pop $_{1}^{4-x}$ else $S_{\text {gen }}^{\text {optimum }}=$ $\operatorname{pop}_{2}^{4-x}$.

\subsection{Medupi Power plant}

The Medupi power plant is a greenfield coal fired power plant project situated in the Limpopo province. On completion, it is expected to be the fourth largest coal plant in the world. It has an installed capacity of 4764 MW from its six units each capable of outputting 794 MW. Unit 6 (the first of the 6 units) was synchronized with the grid in 2015. It has a planned operational lifetime of about 50 years [19, 18]. In evaluating statistics such as loading factor, operations cost, environmental costs $\left(\varepsilon^{t}, F^{O P \operatorname{cost}}, F^{E \cos t}\right)$ etc., there was the need to be able to characterize the behaviour of the Medupi power plant under varying loading conditions. A modified artificial neural network MANN [38] was applied on data plot describing the evolution of the levelized cost of energy for various power plants [14] to generate constants a and b as shown in Table 4. The choice and use of the Medupi power plant is because of its proximity to the customers being considered. Furthermore, its capacity is capable of dispatching the baseload and DSM loads of the considered consumers hence its choice. 


\section{Results and discussion}

In modelling the allocation of consumer loads based on their selected and optimized parameters (dispatch option 1), a controlled allocation (dispatch option 2) was also done to provide a basis for comparison and standardization. The controlled allocation (dispatch option 2) assumes $w_{i}=3$ (i.e. the utility selects the start time of participating DSM loads) for all customers with all other selections remaining the same (under the user's control). Table 7 presents the distribution of households across the various classes under both dispatch options (1 and 2) while Table 8 presents the distribution of houses across the various dispatch windows.

Table 9 presents the values of associated parameters for both dispatch options (1 and 2). It is observed from Table 9 that dispatch option 2 achieves a better minimization of $C^{D S M}$ of $14.94 M W$ compared to a peak $C^{D S M}$ of $40.77 M W$ for dispatch option 1. In terms of plant utilization $\left(U^{u t i l}\right)$, dispatch option 2 also produces a better value of $87.92 \%$ compared to $86.30 \%$ by dispatch option 1 . The operations cost $\left(F^{O P \operatorname{cost}}\right)$ is higher for dispatch option 1 compared to dispatch option 2 while dispatch option 1 is more environmentally friendly with $F^{\text {Ecost }}$ of ZAR 11,288,439 compared to ZAR 11,501,166 by dispatch option 2. Dispatch option 1 was also found to be more consumer friendly from Table 10 under dynamic pricing with a total cumulative cost for the DSM loads $\left(P^{D P}\right)$ of ZAR $373,218.40$ to the residential houses. This is in contrast to a $\left(P^{D P}\right)$ of ZAR $416,280.20$ from dispatch option 2. However, dispatch option 2 provided a better fixed price cost $\left(P^{F P}\right)$ of ZAR $433,185.30$ compared to dispatch option 1's fixed price cost of ZAR 438,153.40.

The area plots shown in Figures 10 and 11 depict the cumulative load profile (base load, cloth washer, cloth dryer and dish washer) for both dispatch options (1 and 2) respectively. The computation of the actual cloth washer value is done by deducting the read out cloth washer value from the plot and deducting the base value from it. Also, the computation of the cloth dryer value is done by deducting from the read out cloth dryer plot value the cumulative sum of the base load value and the corresponding cloth washer value. The actual dish washer value is computed by deducting from the dish washer plot value the cumulative sum of the base load value and the corresponding cloth washer and cloth dryer values. It is observed from Figure 10 that its profile is influenced greatly by the dynamic pricing curve. With over $50 \%$ of households selecting class 2 , the utility is given more leverage to shift dispatch time of DSM loads away from the early hours of the day to periods of low prices. However, for selections that must be done within the periods of high cost, the utility is forced to optimally schedule the DSM loads to be dispatched at periods with lower costs. This is however done within the limits allowed by the other prevailing constraining parameters $\left(F^{E \cos t}, F^{O P \operatorname{cost}}\right.$ etc.). Figure 11 however presents a profile which is evenly distributed across the day irrespective of the dynamic pricing profile. This explains why the $P^{D P}$ for dispatch option 2 is higher than that for dispatch option 1 as shown in Table 9.

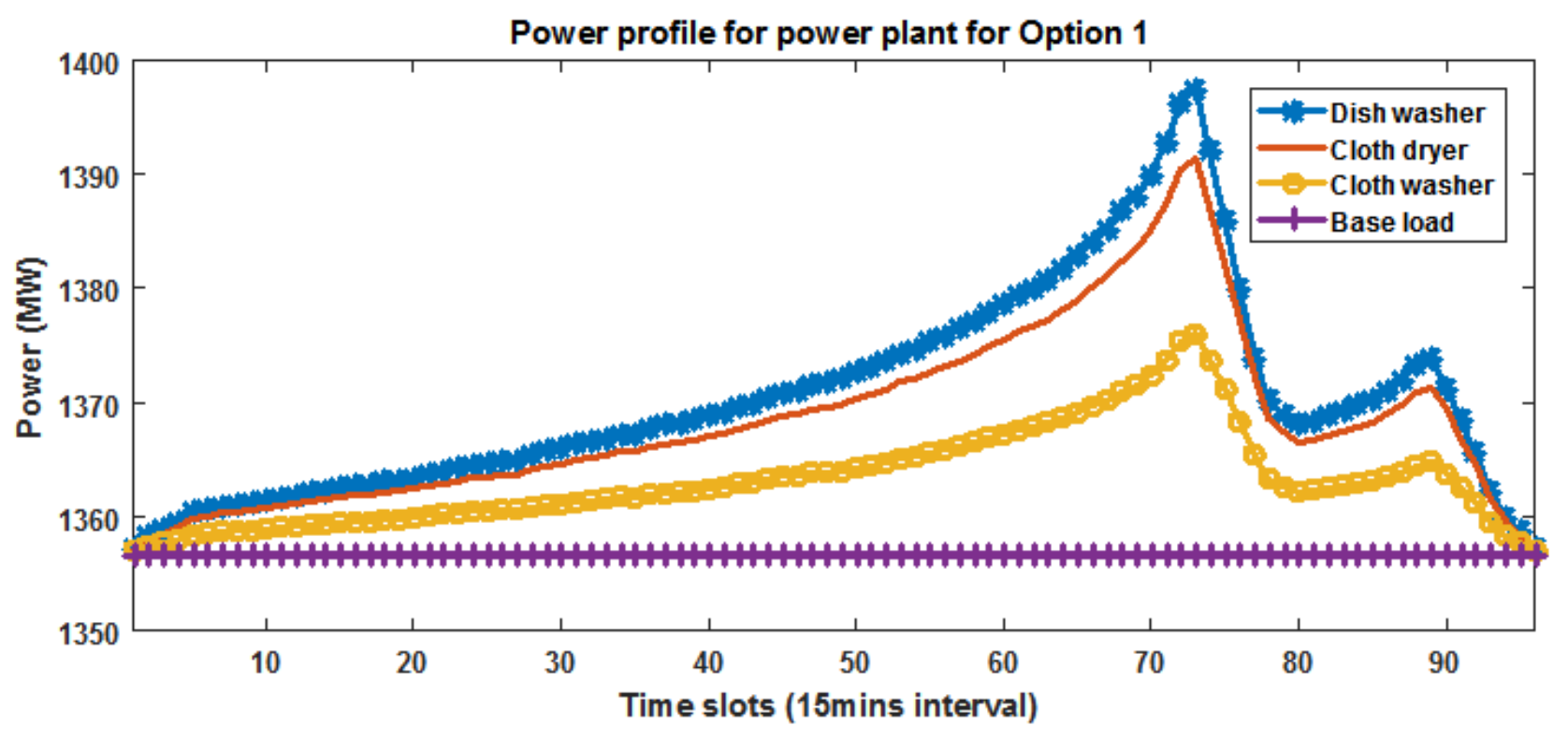

Figure 10: Option 1 cumulative power profile. 


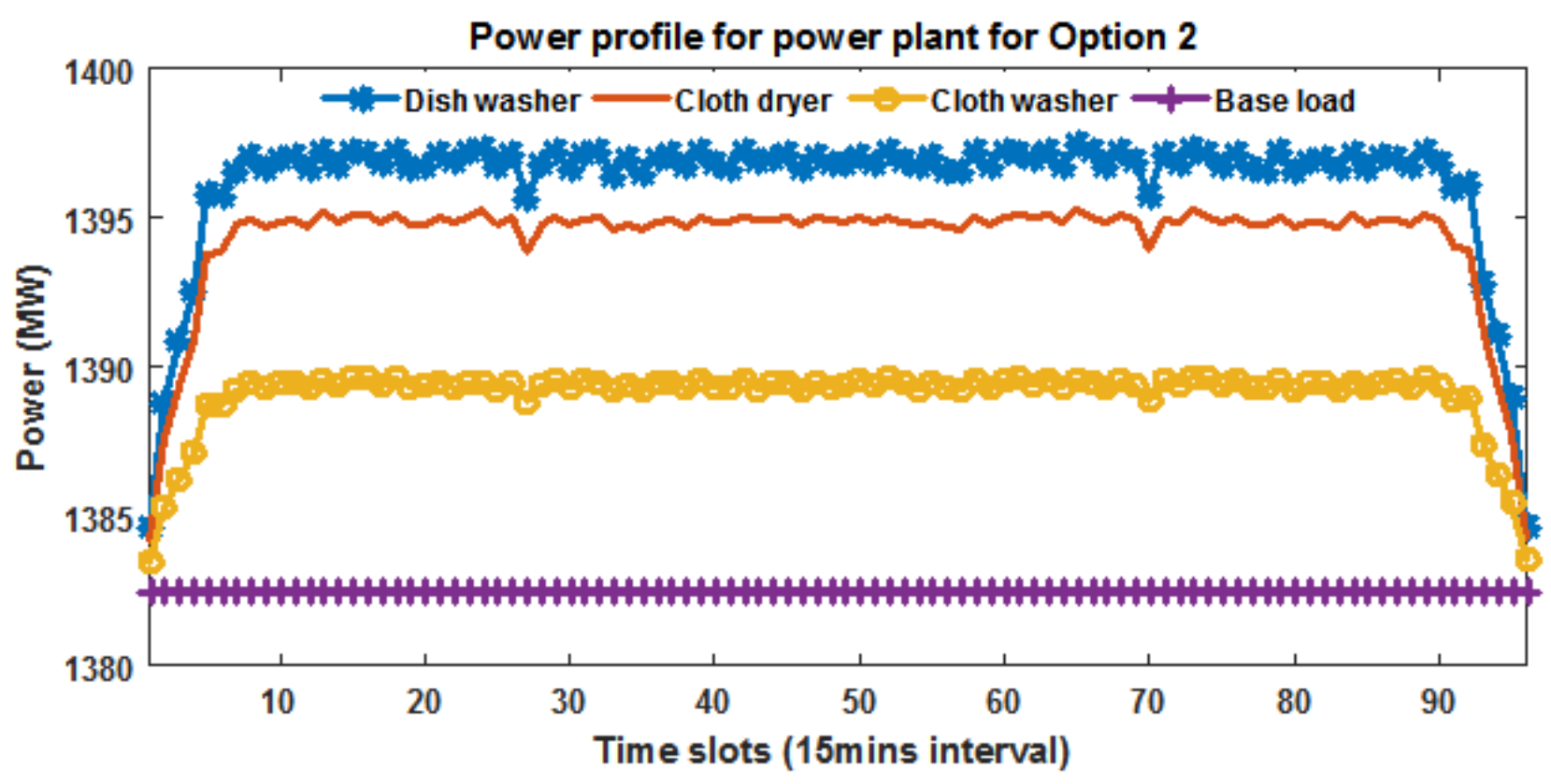

Figure 11: Option 2 cumulative power profile.

In evaluating the actual expenditure and potential savings (if any) for both options, the associated energy $\left(E_{i}^{\text {energy }}\right)$, dynamic pricing cost $\left(P_{i}^{D P}\right)$ and fixed price cost $\left(P_{i}^{F P}\right)$ for selected houses for both dispatch options 1 and 2 are shown in Table 10. It is important to point out that the costs shown in the Table 10 are primarily for the DSM loads under consideration (cloth washer, cloth dryer and dish washer) and are independent of standing charges and other associated costs. From Table 10, it is noticed that dispatch option 1 achieves daily savings of $6.5 \%, 19.7 \%, 39.2 \%, 44 \%, 31.7 \%$ and $29.5 \%$ for houses 1, 1000, 10000, 25000, 33000 and 71000 . Furthermore, a higher dynamic cost is observed for the house 7 under dispatch option 1 out of the ten houses under consideration. However, dispatch option 2 has more houses (4) compared to dispatch option 1 (1) incurring higher electricity cost using dynamic pricing for the houses under consideration.

Table 11 presents the disparity in dispatch time $\left(t_{i, j}^{\text {dispatch }}\right)$ for each DSM appliance under both dispatch options ( 1 and 2 ) for the houses under consideration. The variation in the dispatch time evaluated for both dispatch options (1 and 2) is further depicted in Figure 12, which presents the dispatch (power) of the three DSM appliances for house 1 for both dispatch options (1 and 2). House 1 dispatch of participating DSM loads (cloth washer, cloth dryer and dish washer) under both dispatch options (1 and 2) results in $t_{\text {option } 1 / \text { option } 2}^{\text {dispatch }}=\{59,25\}$ for cloth washer, $t_{\text {option } 1 / \text { option } 2}^{\text {dispatch }}=\{85,34\}$ for cloth dryer and $t_{\text {option } 1 / \text { option } 2}^{\text {dispatch }}=\{42,92\}$ for dish washer. The computation of the standard deviation for the dispatch values gives 17.68 for dispatch option 1 and 30 for dispatch option 2 which implies that the utility achieves a better spread of the dispatch times and also achieves a $23.8 \%$ savings (for dispatch option 2 ) compared to a $6.46 \%$ savings (for dispatch option 1 ).

\section{$7 \quad$ Policy discussion on results}

As earlier highlighted among the HEMS and SSEMS objectives, electricity cost reduction and greater system flexibility are some overaching reasons for proposing the integration of SSEMS and HEMS. Considering the implications of [37] which shows declining electricity per capita values and [13] where it can be argued that planned capacity expansion might be over-sized, we present some implications of the results obtained on the consumer and the supply side.

\subsubsection{Policy implication of CEMS on consumers}

Results obtained from CEMS modelling (that integrates HEMS and SSEMS constraints) show that averagely, reduction in electricity bills of consumers is guaranteed for CEMS platform that incorporates dynamic pricing. The introduction of dispatch windows and the incorporation of dynamic pricing mean homeowners are not forced to avoid electricity usage during peak hours due to higher electricity prices under TOU pricing. For example, results from Table 10 show that on average, dispatch option 1 saves each participating house $519.48 \mathrm{Wh} / \mathrm{day}$ with dispatch option 2 saving $135.24 W h /$ day. 


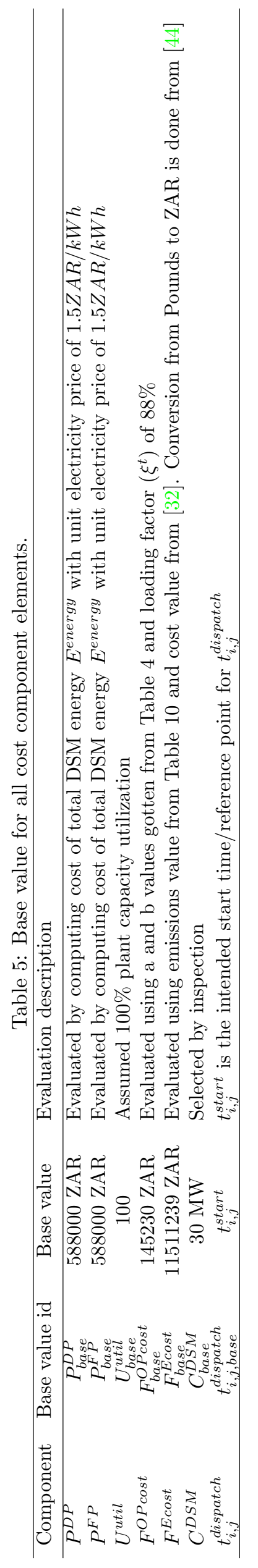


Table 6: SSEMS-HEMS conflict matrix

\begin{tabular}{cccc}
\hline & & \multicolumn{3}{c}{ HEMS } \\
& & 1 & 2 \\
\hline & 1 & & $\checkmark$ \\
& 2 & & $\checkmark$ \\
SSEMS & 3 & & \\
& 4 & $\checkmark$ & $\checkmark$ \\
& 5 & $\checkmark$ & \\
\hline
\end{tabular}

Table 7: Household class $k_{i}$ distribution for the various options

\begin{tabular}{cccc}
\hline & \multicolumn{3}{c}{ Class $k_{i}$} \\
Option & 1 & 2 & 3 \\
\hline 1 & 24887 & 50185 & 24928 \\
2 & 24887 & 50185 & 24928 \\
\hline
\end{tabular}

Table 8: Household dispatch window $w_{i}$ distribution for the various options

\begin{tabular}{cccc}
\hline & \multicolumn{3}{c}{ Dispatch window $w_{i}$} \\
Option & 1 & 2 & 3 \\
\hline 1 & 25043 & 50037 & 24920 \\
2 & 0 & 0 & 100000 \\
\hline
\end{tabular}

Table 9: Associated parameter values for the various options

\begin{tabular}{lcc}
\hline & \multicolumn{2}{c}{ Options } \\
Parameters & 1 & 2 \\
\hline Baseload, $C^{B L}(\mathrm{MW})$ & 1356.67 & 1382.50 \\
Plant utilization, $U^{\text {util }}(\%)^{* *}$ & 86.30 & 87.92 \\
Peak $C^{D S M}(\mathrm{MW})$ & 40.77 & 14.94 \\
Cumulative Energy, $E^{\text {energy }}(M W h)^{*}$ & 329.31 & 329.31 \\
$F^{O P \operatorname{cost}}(Z A R)^{* *}$ & 147640.50 & 145329.80 \\
$F^{\text {Ecost }}(Z A R)^{* *}$ & 11288439 & 11501166 \\
$P^{D P}(Z A R)^{*}$ & 373218.40 & 416280.20 \\
$P^{F P}(Z A R)^{*}$ & 438153.40 & 433185.30 \\
\hline * DSM loads only & & \\
** - DSM + baseloads & & \\
& &
\end{tabular}




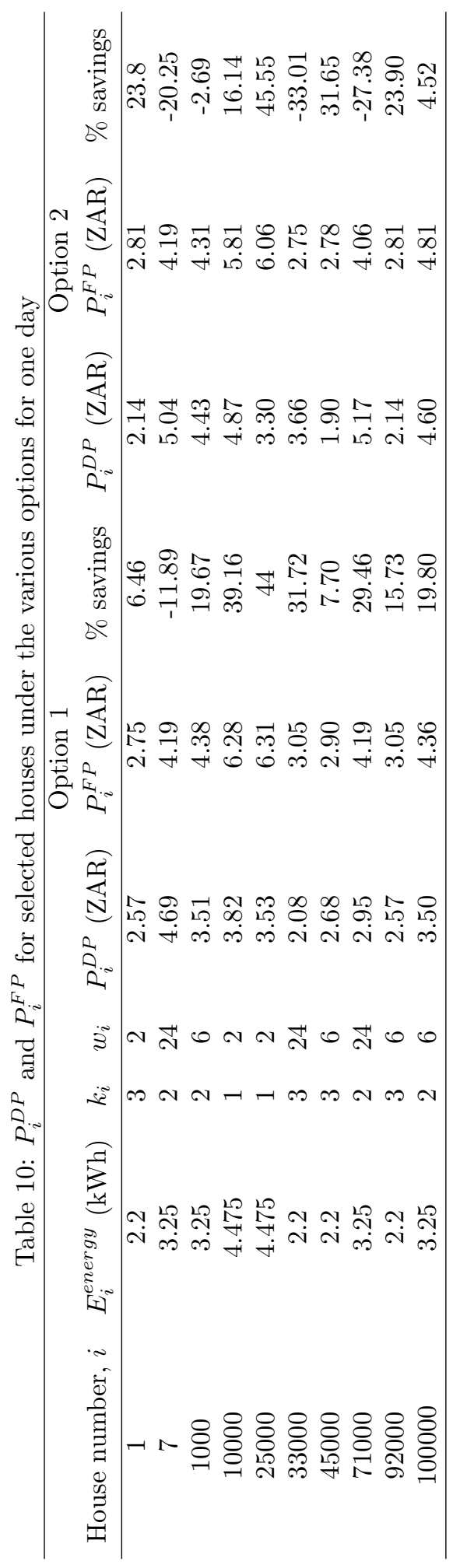


The benefit of this is that homeowners could either extend usage of owned electrical appliances or direct the savings to other activities that improve their Quality of Life (QoL).

\subsubsection{Policy implication of CEMS on electricity suppliers}

A major problem in electricity generation and supply is in sizing spinning reserves. Mostly, reserve margins are oversized in anticipation of demand increase which leads to higher operations cost, environmental costs and inefficiency. Providing the electricity supplier with some control over dispatch times of consumer loads (participating in DSM) offers the supply side greater flexibility in optimally scheduling generation resources. From Table 9, dispatch option 2 achieves a 1.6\% reduction in operations cost over dispatch option 1 with dispatch option 2 achieving a better operations profile as shown in Figure 11.

Table 11: $t_{i, j}^{\text {dispatch }}$ for selected houses under the various options

\begin{tabular}{ccccccc}
\hline & \multicolumn{2}{c}{ Cloth washer } & \multicolumn{2}{c}{ Cloth dryer } & \multicolumn{2}{c}{ Dish washer } \\
\hline House number, $i$ & $t_{\text {Option } 1}^{\text {dispatch }}$ & $t_{\text {Option } 2}^{\text {dispatch }}$ & $t_{\text {Option } 1}^{\text {dispatch }}$ & $t_{\text {Option2 } 2}^{\text {dispatch }}$ & $t_{\text {Option } 1}^{\text {dispatch }}$ & $t_{\text {Option } 2}^{\text {dispatch }}$ \\
\hline 1 & 59 & 25 & 85 & 34 & 42 & 92 \\
7 & 29 & 29 & 48 & 52 & 53 & 9 \\
1000 & 46 & 28 & 73 & 66 & 56 & 42 \\
10000 & 76 & 21 & 60 & 15 & 72 & 89 \\
25000 & 33 & 17 & 78 & 74 & 74 & 82 \\
33000 & 33 & 14 & 60 & 9 & 76 & 38 \\
45000 & 58 & 20 & 38 & 93 & 67 & 63 \\
71000 & 71 & 50 & 5 & 11 & 87 & 7 \\
92000 & 33 & 35 & 40 & 32 & 73 & 92 \\
100000 & 55 & 19 & 56 & 69 & 68 & 28 \\
\hline
\end{tabular}

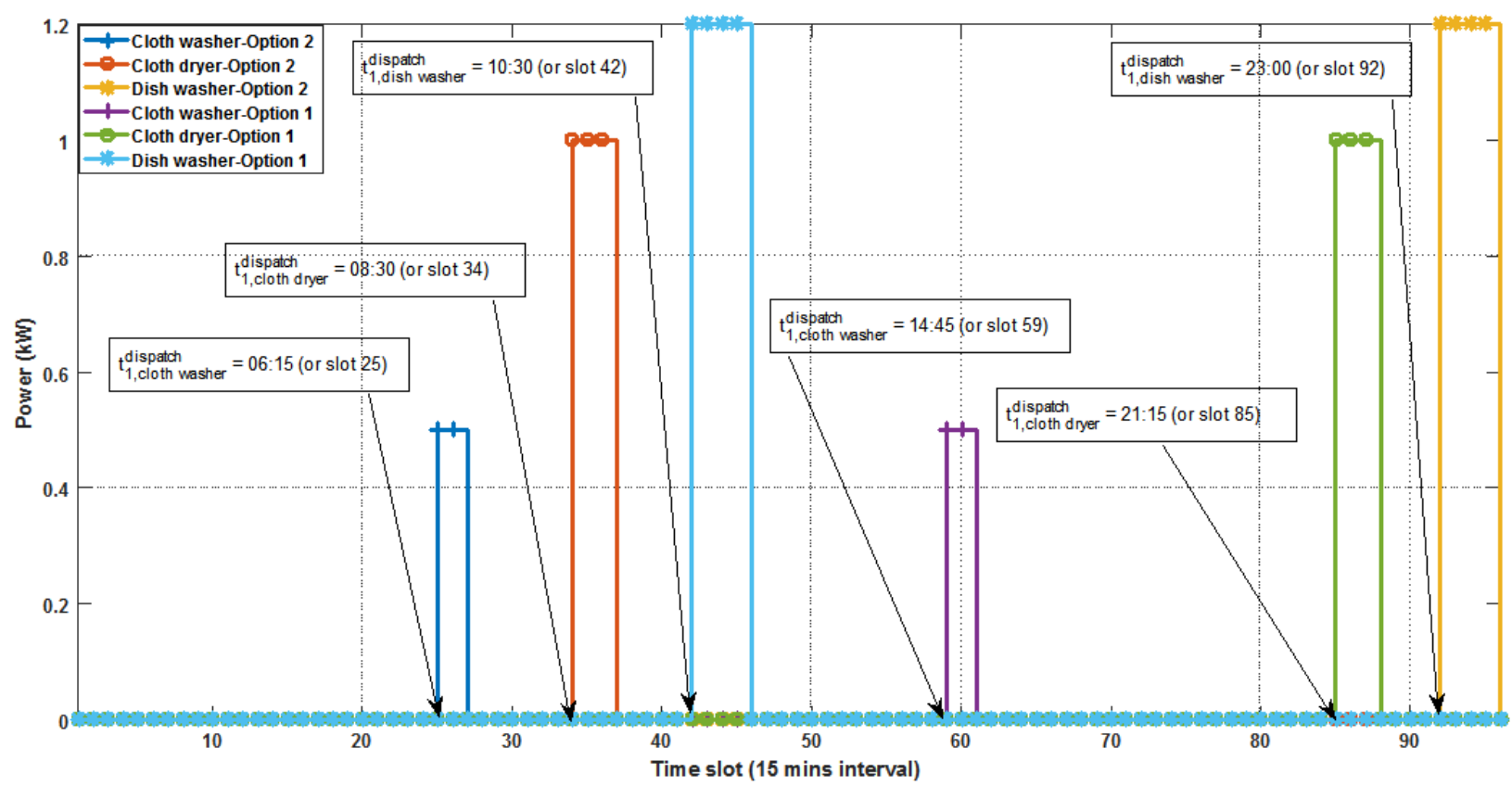

Figure 12: Options 1 and 2 dispatch profile for house 1 DSM loads.

\section{Conclusion}

This research work has presented in detail the optimization of a DSM window on the Medupi power plant, for 100000 residential houses in South Africa. Using a CEMS (which incorporates a SDBGA), a synergy between HEMS and SSEMS has been established as well as the resolution of the ensuing SSEMS-HEMS conflict matrix. Two Options have been modelled (with dispatch option 2 acting as a control for the standardization of the proposed model) for all residential houses and DSM loads. A critical evaluation of the two options shows that 
dispatch option 1 outperforms dispatch option 2 in minimizing $F^{\text {Ecost }}$ and $P^{D P}$. Furthermore, dispatch option 1 has been shown to be sensitive to the dynamic pricing model adopted as it strives to shift dispatch of consumer loads from the periods of higher costs to periods of lower costs. This is at variance with dispatch option 2 which is quite insensitive to the dynamic pricing model and strives to achieve an evenly distributed profile and minimized DSM window at the expense of higher consumer and environmental costs. Average overall plant capacity utilization by dispatch option 1 has also been shown to be $86.3 \%$ which competes favourably with $87.92 \%$ obtained by dispatch option 2 .

This research has thus shown that handing over total control of the dispatch time of participating DSM loads to the utility (dispatch option 2 ) is at variance with the aim of dynamic pricing. This is due to the reasons deduced from Table 9 where dispatch option 2 is seen to strive for a very strict minimized DSM window with the consequence of higher environmental costs and higher dynamic price cost due customers. This thus defeats the incentive behind price based demand response. However, this research has shown that the variability in consumers choice of dispatch start times and dispatch windows introduces robustness to the model and enhances its ability to search for an optimal solution with significant benefits to both the consumers and suppliers.

In extending this research, a multi-DSM window is being exploited with varying dynamic pricing schemes to see how well this proposed model performs under such multi-complex situation.

\section{General applicability}

While this work has utilized statistics relating to South Africa to test the proposed CEMS model, CEMS is of general application. This is because the associated statistics such as DSM loads, window, class, number of participating houses etc. are all plug-ins and do not interfere with the model description but are rather used in optimizing the dispatch of DSM loads based on pre-determined criteria.

\section{Acknowledgement}

The financial assistance of the National Research Foundation (NRF) and The World Academy of Sciences (TWAS) through the DST-NRF-TWAS doctoral fellowship towards this research is hereby acknowledged. Opinions expressed and conclusions arrived at, are those of the authors and are not necessarily to be attributed to the NRF. The authors also appreciate the anonymous reviewers for their helpful comments.

\section{References}

[1] G.R. Aghajani, H.A. Shayanfar, and H. Shayeghi. "Demand side management in a smart micro-grid in the presence of renewable generation and demand response". In: Energy 126 (2017), pp. 622 -637. ISSN: 03605442. DOI: https://doi.org/10.1016/j . energy . 2017.03 .051. URL: http://www . sciencedirect . com/science/article/pii/S0360544217304139.

[2] K. Al-jabery et al. "Demand-Side Management of Domestic Electric Water Heaters Using Approximate Dynamic Programming". In: IEEE Transactions on Computer-Aided Design of Integrated Circuits and Systems 36.5 (2017), pp. 775-788. ISSN: 0278-0070. DOI: 10.1109/TCAD.2016.2598563.

[3] Rajeev Alasseri et al. "A review on implementation strategies for demand side management (DSM) in Kuwait through incentive-based demand response programs". In: Renewable and Sustainable Energy Reviews 77 (2017), pp. 617 -635. ISSN: 1364-0321. DOI: https://doi.org/10.1016/j.rser.2017.04.023. URL: http://www.sciencedirect.com/science/article/pii/S1364032117305282.

[4] M.H. Alham et al. "Optimal operation of power system incorporating wind energy with demand side management". In: Ain Shams Engineering Journal 8.1 (2017), pp. 1 -7. ISSN: 2090-4479. DOI: https: //doi.org/10.1016/j.asej.2015.07.004. URL: http://www.sciencedirect.com/science/article/ $\mathrm{pii} / \mathrm{S} 2090447915001094$.

[5] S. Althaher, P. Mancarella, and J. Mutale. "Automated Demand Response From Home Energy Management System Under Dynamic Pricing and Power and Comfort Constraints". In: IEEE Transactions on Smart Grid 6.4 (2015), pp. 1874-1883.

[6] Alessia Arteconi et al. "Thermal energy storage coupled with $\{\mathrm{PV}\}$ panels for demand side management of industrial building cooling loads". In: Applied Energy 185, Part 2 (2017). Clean, Efficient and Affordable Energy for a Sustainable Future, pp. 1984 -1993. Issn: 0306-2619. DoI: https ://doi .org/10 . 1016/j . apenergy . 2016.01 .025. URL: http : / / www . sciencedirect. com/science/article/pii / S0306261916300058. 
[7] Marc Beaudin and Hamidreza Zareipour. "Home energy management systems: A review of modelling and complexity". In: Renewable and Sustainable Energy Reviews 45 (2015), pp. 318 -335. ISSN: 1364-0321. DOI: https ://doi.org/10.1016/j.rser.2015.01.046. URL: http://www.sciencedirect.com/science/ article/pii/S1364032115000568.

[8] Nina Boogen, Souvik Datta, and Massimo Filippini. "Demand-side management by electric utilities in Switzerland: Analyzing its impact on residential electricity demand". In: Energy Economics (2017), pp. - . ISSN: 0140-9883. DOI: https : / / doi . org / 10 . 1016/j . eneco . 2017 .04 .006. URL: http : / / ww . sciencedirect.com/science/article/pii/S0140988317301123.

[9] S. Chakraborty and T. Okabe. "Optimal demand side management by distributed and secured energy commitment framework". In: IET Generation, Transmission Distribution 10.14 (2016), pp. 3610-3621. ISSN: 1751-8687. DOI: 10.1049/iet-gtd.2016.0413.

[10] A. C. Chapman, G. Verbi, and D. J. Hill. "Algorithmic and Strategic Aspects to Integrating DemandSide Aggregation and Energy Management Methods". In: IEEE Transactions on Smart Grid 7.6 (2016), pp. 2748-2760. ISSN: 1949-3053. DOI: 10.1109/TSG.2016.2516559.

[11] Fathia Chekired et al. "An Energy Flow Management Algorithm for a Photovoltaic Solar Home". In: Energy Procedia 111.Supplement C (2017). 8th International Conference on Sustainability in Energy and Buildings, SEB-16, 11-13 September 2016, Turin, Italy, pp. 934 -943. ISSN: 1876-6102. DOI: https: // doi .org/10 .1016/j . egypro.2017.03 . 256. URL: http: //www . sciencedirect . com/science / article/pii/S1876610217302898.

[12] Y. Cong et al. "On the Use of Dynamic Thermal-Line Ratings for Improving Operational Tripping Schemes". In: IEEE Transactions on Smart Grid 31.4 (2016), pp. 1891-1900.

[13] CSIR. Forecasts for electricity demand in South Africa (2014 2050) using the CSIR sectoral regression model. Accessed: 2017-04-20. 2016. URL: http : / / www . energy · gov . za / IRP / 2016 / IRP - AnnexureBDemand-forecasts-report.pdf.

[14] DOE. Integrated Resource Plan Update - Assumptions, Base Case Results and Observations (revision 1). Accessed: 2017-04-20. 2016. URL: http : / / www . energy . gov . za / IRP / 2016 / Draft - IRP - 2016 Assumptions-Base-Case-and-Observations-Revision1.pdf.

[15] Eskom. Compact fluorescent lamp rollout. [Online] Accessed: 2017-04-20. URL: http: //www . eskom . co . $\mathrm{za} / \mathrm{sites} / \mathrm{idm} /$ Residential/Pages/CFLRollout. aspx.

[16] Eskom. Concentrating Solar Power. [Online] Accessed: 2017-04-20. URL: http : //www . eskom . co . za / AboutElectricity / RenewableEnergy / ConcentratingSolarPower / Pages / Concentrating _ Solar _ Power_CSP. aspx.

[17] Eskom. Kusile Power Station Project. [Online] Accessed: 2017-05-18. URL: http: //www.eskom.co.za/ Whatweredoing/NewBuild/Pages/Kusile_Power_Station.aspx.

[18] Eskom. Medupi Power Station. Tech. rep. [Online] Accessed: 2017-09-15. Eskom, 2013. URL: http: //www . eskom.co.za/Whatweredoing/NewBuild/MedupiPowerStation/Documents/BROCHUREmedupipowerstationproject . pdf.

[19] Eskom. Medupi produces its first power. Tech. rep. [Online] Accessed: 2017-09-15. Eskom, 2015. URL: http://www. eskom.co.za/news/Pages/MedupiSync . aspx.

[20] Eskom. Sere Wind Farm project. [Online] Accessed: 2017-04-20. URL: http : / / www . eskom . co . za / AboutElectricity/RenewableEnergy/Pages/SereWindFarm.aspx.

[21] Eskom. Solar energy. [Online] Accessed: 2017-04-20. URL: http://www. eskom. co.za/IDM/EskomSolarWaterHeatingPr Pages/Solar_Water_Heating_Programme.aspx.

[22] Eskom. Transmission Development Plan 2016-2025. [Online] Accessed: 2017-05-18. URL: http: //www . eskom.co.za/Whatweredoing/TransmissionDevelopmentPlan/Documents/TransDevPlan2016-2025Brochure. pdf.

[23] Eskom wants to mothball five plants. [Online] Accessed: 2017-05-18. URL: http : //www . iol . co . za / business-report/energy/eskom-wants-to-mothball-five-plants-8180946.

[24] J. Gunda and S. Djokic. "Coordinated control of generation and demand for improved management of security constraints". In: in proceedings of 2016 IEEE PES Innovative Smart Grid Technologies Conference Europe (ISGT-Europe). 2016, pp. 1-6.

[25] A. Hajimiragha et al. "Optimal Energy Flow of integrated energy systems with hydrogen economy considerations". In: 2007 iREP Symposium - Bulk Power System Dynamics and Control - VII. Revitalizing Operational Reliability. 2007, pp. 1-11. DOI: 10.1109/IREP.2007.4410517. 
[26] Yumiko Iwafune et al. "Energy-saving effect of automatic home energy report utilizing home energy management system data in Japan". In: Energy 125 (2017), pp. 382 -392. ISSN: 0360-5442. DOI: https: //doi .org/10.1016/j . energy . 2017 .02 .136. URL: http://www. sciencedirect.com/science/ article/pii/S0360544217303195.

[27] Bo Jiang et al. "Demand side management in power grid enterprise control: A comparison of industrial \&amp; social welfare approaches". In: Applied Energy 187 (2017), pp. 833 -846. ISSN: 0306-2619. DOI: https : / / doi .org/10.1016/j . apenergy . 2016 . 10.096. URL: http:// www . sciencedirect . com / science/article/pii/S0306261916315410.

[28] K. Karunanithi et al. "Integration of Demand and Supply Side Management strategies in Generation Expansion Planning". In: Renewable and Sustainable Energy Reviews 73 (2017), pp. 966 -982. ISSN: 13640321. DOI: https://doi.org/10.1016/j.rser.2017.01.017. URL: http://www. sciencedirect.com/ science/article/pii/S1364032117300187.

[29] R. Kernan et al. "Demand side management of an urban water supply using wholesale electricity price". In: Applied Energy 189 (2017), pp. 395 -402. ISSN: 0306-2619. DOI: https://doi.org/10.1016/j .apenergy . 2016.12.082. URL: http://www.sciencedirect.com/science/article/pii/S0306261916318566.

[30] Marcel Kohler. "Differential electricity pricing and energy efficiency in South Africa". In: Energy 64 (2014), pp. 524-532. DOI: 10.1016/j.energy .2013.11.047. URL: http://linkinghub.elsevier.com/ retrieve/pii/S0360544213010177.

[31] Dimitrije Kotur and eljko urii. "Optimal spatial and temporal demand side management in a power system comprising renewable energy sources". In: Renewable Energy 108 (2017), pp. 533 -547. IssN: 0960-1481. DOI: https : //doi .org/10.1016/j.renene.2017.02.070. URL: http://www . sciencedirect . com/ science/article/pii/S0960148117301568.

[32] E. T. Lau et al. "Optimization of carbon emissions in smart grids". In: 2014 49th International Universities Power Engineering Conference (UPEC). 2014, pp. 1-4. DOI: 10.1109/UPEC.2014.6934796.

[33] Loadshedding to run from 8am to 10pm today. [online] Accessed: 2017-05-01. URL: http://www.htxt.co. za/2015/05/21/loadshedding-to-run-from-8am-to-10pm-today/.

[34] L. Martirano et al. "Demand Side Management in Micro-grids for Load Control in Nearly Zero Energy Buildings". In: IEEE Transactions on Industry Applications PP.99 (2017), pp. 1-1. ISSN: 0093-9994. DOI: 10.1109/TIA. 2017.2672918.

[35] Mousa Marzband et al. "A real-time evaluation of energy management systems for smart hybrid home Microgrids". In: Electric Power Systems Research 143 (2017), pp. 624 -633. IsSn: 0378-7796. DOI: https: //doi.org/10.1016/j.epsr.2016.10.054. URL: http://www.sciencedirect.com/science/article/ $\mathrm{pii} / \mathrm{S} 0378779616304618$.

[36] Saeed Mohajeryami et al. "A novel economic model for price-based demand response". In: Electric Power Systems Research 135 (2016), pp. 1 -9. ISSN: 0378-7796. DOI: https://doi.org/10.1016/j.epsr. 2016. 03.026. URL: http://www.sciencedirect.com/science/article/pii/S0378779616300736.

[37] C.G. Monyei and A.O. Adewumi. "Demand Side Management potentials for mitigating energy poverty in South Africa". In: Energy Policy 111.Supplement C (2017), pp. 298 -311. ISSN: 0301-4215. DOI: https: // doi .org/10 .1016/j . enpol . 2017.09.039. URL: http: //www . sciencedirect . com/science / article/pii/S0301421517305992.

[38] Chukwuka G. Monyei, Aderemi O. Adewumi, and Michael O. Obolo. "Oil Well Characterization and Artificial Gas Lift Optimization Using Neural Networks Combined with Genetic Algorithm". In: Discrete Dynamics in Nature and Society 2014 (2014), pp. 1-10. DOI: http://dx.doi.org/10.1155/2014/289239.

[39] Ofgem. Making the electricity system more flexible and delivering the benefits for consumers. Accessed: 2017-04-20. London., 2015. URL: https://www. ofgem.gov.uk/ofgem-publications/96959/flexibilitypositionpa pdf.

[40] A.S.O. Ogunjuyigbe, T.R. Ayodele, and O.A. Akinola. "User satisfaction-induced demand side load management in residential buildings with user budget constraint". In: Applied Energy 187 (2017), pp. 352 -366. ISSN: 0306-2619. DOI: https : / / doi .org/10.1016/j . apenergy . 2016.11 .071. URL: http: //www.sciencedirect.com/science/article/pii/S0306261916317020.

[41] A.S.O. Ogunjuyigbe, T.R. Ayodele, and C.G. Monyei. "An intelligent load manager for $\{\mathrm{PV}\}$ powered off-grid residential houses". In: Energy for Sustainable Development 26 (2015), pp. 34 -42. ISSN: 09730826. DOI: https://doi.org/10.1016/j.esd.2015.02.003. URL: http://www.sciencedirect.com/ science/article/pii/S0973082615000113. 
[42] A.S.O. Ogunjuyigbe, C.G. Monyei, and T.R. Ayodele. "Price based demand side management: A persuasive smart energy management system for low/medium income earners". In: Sustainable Cities and Society 17 (2015), pp. 80 -94. ISSN: 2210-6707. DOI: http://doi.org/10.1016/j .scs . 2015.04 .004$. URL: http://www. sciencedirect.com/science/article/pii/S221067071500044X.

[43] Andrew D. Peacock et al. "Co-designing the next generation of home energy management systems with lead-users". In: Applied Ergonomics 60 (2017), pp. 194 -206. ISSN: 0003-6870. DOI: https ://doi.org/ 10.1016/j . apergo.2016.11 .016. URL: http://www . sciencedirect . com/science/article/pii/ S0003687016302599.

[44] SARB. SARB Exchange Rate. [Online] Accessed: 2017-04-24. URL: https://www.resbank.co.za/Pages/ default.aspx.

[45] Mohammad Shakeri et al. "An intelligent system architecture in home energy management systems (HEMS) for efficient demand response in smart grid". In: Energy and Buildings 138 (2017), pp. 154 -164. ISSN: 0378-7788. DOI: https : / / doi . org/10 . 1016/ j . enbuild . 2016 . 12 . 026. URL: http : //www.sciencedirect.com/science/article/pii/S0378778816318369.

[46] R. Sharifi, S.H. Fathi, and V. Vahidinasab. "A review on Demand-side tools in electricity market". In: Renewable and Sustainable Energy Reviews 72 (2017), pp. 565 -572. ISSN: 1364-0321. DOI: https://doi. org/10.1016/j.rser.2017.01.020. URL: http://www.sciencedirect.com/science/article/pii/ S1364032117300230.

[47] Daniel L. Summerbell et al. "Cost and carbon reductions from industrial demand-side management: Study of potential savings at a cement plant". In: Applied Energy 197 (2017), pp. 100 -113. ISSN: 0306-2619. DOI: https://doi.org/10.1016/j.apenergy .2017.03.083. URL: http://www . sciencedirect.com/ science/article/pii/S0306261917303240.

[48] Fei Yang and Xiaohua Xia. "Techno-economic and environmental optimization of a household photovoltaicbattery hybrid power system within demand side management". In: Renewable Energy 108 (2017), pp. 132 -143. ISSN: 0960-1481. DOI: https : //doi .org/10.1016/j .renene.2017 .02 .054. URL: http: //www . sciencedirect.com/science/article/pii/S0960148117301404.

[49] Bin Zhou et al. "Smart home energy management systems: Concept, configurations, and scheduling strategies". In: Renewable and Sustainable Energy Reviews 61 (2016), pp. 30 -40. ISSN: 1364-0321. DoI: https: //doi.org/10.1016/j.rser.2016.03.047. URL: http://www.sciencedirect.com/science/article/ pii/S1364032116002823.

[50] Emmanuel Ziramba. "The demand for residential electricity in South Africa". In: Energy Policy 36.9 (2008), pp. 3460 -3466. ISSN: 0301-4215. DOI: https://doi.org/10.1016/j.enpol.2008.05.026. URL: http://www.sciencedirect.com/science/article/pii/s0301421508002784. 